Document downloaded from:

http://hdl.handle.net/10251/142038

This paper must be cited as:

Tello-Oquendo, FM.; Navarro-Peris, E.; Gonzálvez-Maciá, J. (09-2). Comparison of the performance of a vapor-injection scroll compressor and a two-stage scroll compressor working with high pressure ratios. Applied Thermal Engineering. 160:1-15.

https://doi.org/10.1016/j.applthermaleng.2019.114023

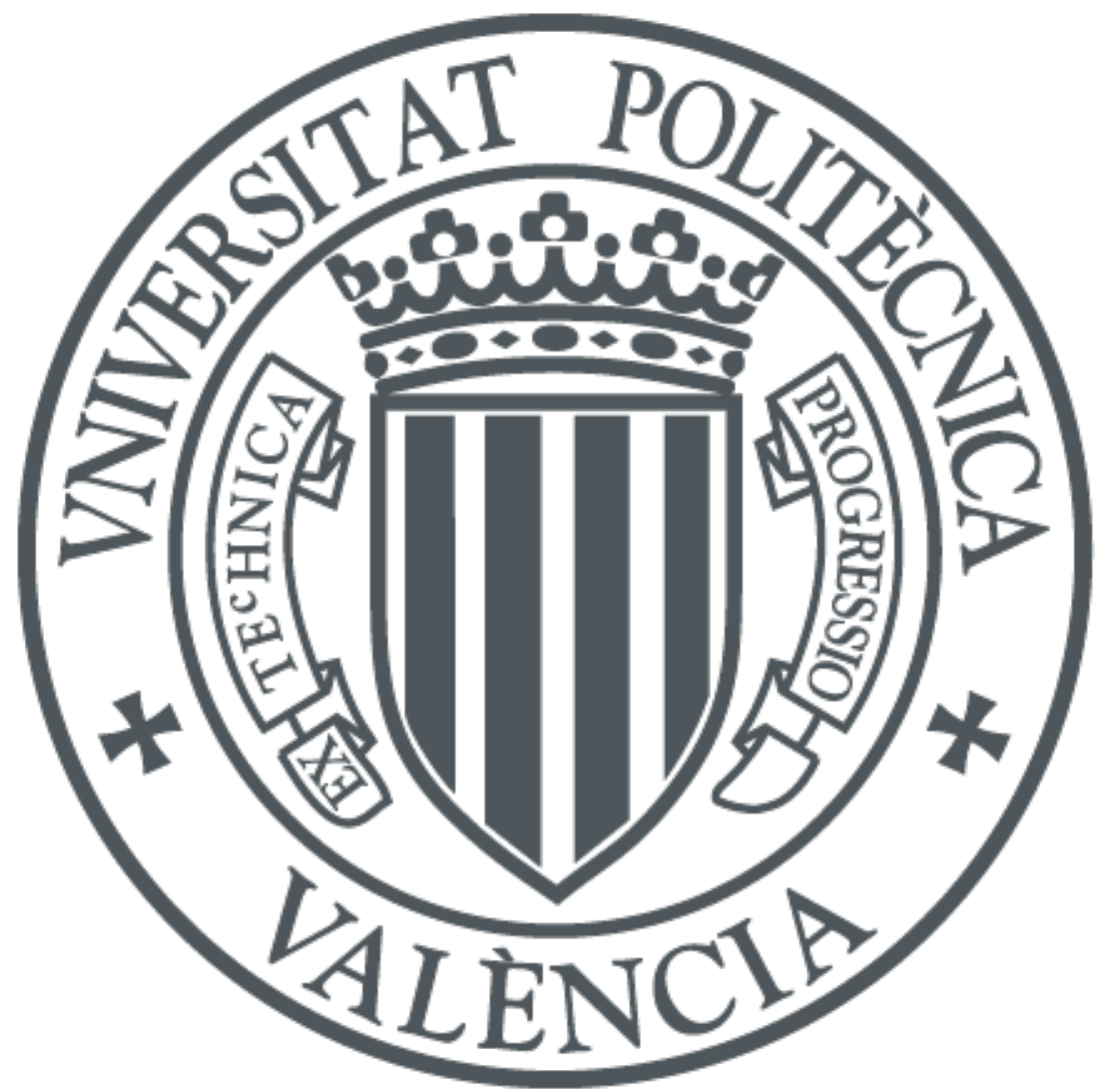

The final publication is available at

https://doi.org/10.1016/j.applthermaleng.2019.114023

Copyright Elsevier

Additional Information 


\title{
Comparison of the performance of a vapor-injection scroll compressor with a two- stage scroll compressor working with high pressure ratios
}

Tello-Oquendo F.M., Navarro-Peris E., Gonzálvez-Maciá J.

\begin{abstract}
This paper presents a comparative analysis of the performance of a vapor-injection scroll compressor (SCVI) and a two-stage scroll compressor (TSSC) working with high pressure ratios in heat pump applications. Semi-empirical models of the compressors are implemented. The models are adjusted with experimental data obtained in a calorimetric test bench. The optimum displacement ratio $\left(D_{R}\right)$ is analyzed considering two criteria, COP maximization, and discharge temperature minimization. Once defined the optimum $D_{R}$, a systematic comparison of the compressors is performed in terms of compressor efficiencies, heating capacity, COP, and discharge temperature. Finally, the intermediate pressure is optimized for a high-temperature water heating application, taking into account heat sink of finite capacity. Results show that the optimum $\mathrm{D}_{\mathrm{R}}$ of TSSC is around 0.58 and the COP is $6 \%$ larger than that the SCVI at the nominal point. Considering a wide range of operating conditions, the SCVI presents better efficiency and COP for pressure ratios below 5. For higher-pressure ratios, the TSSC presents better performance and achieves lower discharge temperature. The heating capacity of the TSSC can be improved by $7 \%$ by varying the swept volume of the high-stage compressor compared with the SCVI, with a minimum effect on the $\mathrm{COP}$ and on the discharge temperature from the optimum conditions.
\end{abstract}

Keywords: two-stage compression, scroll compressor; reciprocating compressor, vaporinjection; optimization; performance comparison 


\section{Introduction}

Heat pumps with a single-stage vapor compression cycle present several limitations when operating with large temperature differences between evaporation and condensation. At high pressure ratios, the performance (COP) and capacity of heat pumps decrease dramatically due mainly to the limitations in the compression process. Under these conditions, the compressor's isentropic and volumetric efficiencies significantly decrease, while the discharge temperature increases. This could compromise the compressor integrity and restrict its operating envelope. On the other hand, the advantage of using heat pumps instead of boilers is diminished, especially for space heating in places with cold climates and for high-temperature water heating applications.

In this context, the use of two-stage compression systems with vapor-injection constitutes an effective solution to improve the performance of heat pumps and to extend the operating envelope of these systems. The two-stage compression allows lower pressure ratios for each compression stage; therefore, each compression stage works closer to its optimum efficiency, which reduces the compressor power input. The vapor-injection technique improves the system capacity and COP and reduces the discharge temperature of the compressor (Xu et al., 2011a).

The scroll compressor with vapor-injection (SCVI) is one of the most used compressor technology in two-stage cycles with vapor-injection. This compressor technology is not exactly a two-stage compressor because it has only one pair of scroll wraps and the refrigerant injection is performed during the compression process in the same pair of scroll wraps. The advantage of SCVI is the easy implementation of vapor-injection from the machining point of view. The refrigerant injection is done through one or more holes (injection ports), which are located in the non-orbiting scroll member to open into the enclosed spaces or pockets formed by the scroll wraps. The size and position of the injection ports define the maximum flow that can be injected between the scroll wraps. The system capacity and the compressor efficiency are maximized by maximizing the injected refrigerant flow.

Numerous studies have been conducted using SCVI in heat pumps and refrigeration systems. Some of the studies have shown the advantages of two-stage cycles with vapor-injection over single-stage cycles. In these studies, the improvements in COP, capacity, and the extension of the work map of the systems are quantified (Ma et al., 2003; Ma and Chai, 2004; Ma and Zhao, 2008; Wang et al., 2009b; Navarro et al., 2013). Other studies have focused on the control and optimization of the system (Wang et al., 2009a and 2009c; Xu et al., 2011b; Cho et al., 2012; Roh and Kim, 2011), and the use of different refrigerants in vapor-injection cycles (Feng et al., 2009; $\mathrm{Xu}$ et al., 2013a, 2013b and 2017). Moreover, the SCVI characterization methodologies have addressed by Winandy and Lebrun, (2002), Navarro et al. (2013) and Tello-Oquendo et al. (2017); and the SCVI modeling by Dutta et al. (2001), Winandy and Lebrun (2002), Wang et al. (2008), Dardenne et al. (2015), Qiao et al. (2015), and James et al. (2016).

Nevertheless, scroll compressors have a fixed built-in volume ratio, which is determined by the scroll geometry. This produces over and under-compression when the operating conditions deviate from the specified design condition. Therefore, the compressors can not work with the optimum efficiency when the operating pressure ratio differs from the design pressure ratio. This fact can reduce the adaptability of the scroll compressor in vapor-injection heat pump applications working with high pressure ratios.

Another possibility to improve the compression process is by using a two-stage scroll compressor (TSSC). This compressor consists of two scroll compressors arranged in series with vapor-injection between the two stages. A few studies have been developed about the application 
of the TSSC in heat pump systems. Park et al. (2006) investigated the effects of refrigerant charge on the performance of a heat pump with two-stage compression for water heating $\left(50{ }^{\circ} \mathrm{C}-55^{\circ} \mathrm{C}\right)$, using river water as a heat source, and R-134a as refrigerant. The system uses a TSSC, an internal heat exchanger (economizer) in the injection mechanism and a flash tank for the intermediate refrigerant mixing. In the heating mode, the capacity increases with the increase of the low-stage EEV opening. However, the low-stage EEV opening is limited by the superheat in the low-stage compressor, which should be between $5 \mathrm{~K}$ and $10 \mathrm{~K}$. The optimum intermediate pressure is obtained when the temperature difference between the condenser and the flash tank is controlled between $28^{\circ} \mathrm{C}$ and $30^{\circ} \mathrm{C}$. The maximum COP is 3.45 at the optimum charge of $10.1 \mathrm{~kg}$.

In the same line, Kwon et al. (2013) studied a heat pump with two-stage compression for district heating using waste energy. The authors analyzed the influence of the heat source temperature and the superheat at the low-stage compressor on the heating capacity and the COP. The system uses a TSSC working with R-134a as refrigerant. These authors found that the COP improves by up to $22.6 \%$ when the heat source temperature is raised from $10{ }^{\circ} \mathrm{C}$ to $30{ }^{\circ} \mathrm{C}$. As the low-stage compressor inlet superheat increases from $2 \mathrm{~K}$ to $11 \mathrm{~K}$, the refrigerant mass flow rate and heating capacity decreases by up to $7.6 \%$ and $2.2 \%$, respectively. However, there is no major impact on the temperature of the hot water produced nor on the COP. Varying the frequency of the high-stage compressor to control the intermediate pressure results in a performance improvement of up to $5.2 \%$ under the same heat source conditions.

Bertsch and Groll (2008) studied an air-source heat pump using a TSSC working with R$410 \mathrm{~A}$ as refrigerant. The heat pump was tested at ambient temperatures as low as $-30{ }^{\circ} \mathrm{C}$ to $10^{\circ} \mathrm{C}$ and supply water temperatures of up to $50{ }^{\circ} \mathrm{C}$ in heating mode. They found that the two-stage mode operation approximately doubles the heating capacity compared with the single-stage mode operation at the same ambient temperature. The discharge temperatures of each compression stage are kept below $105^{\circ} \mathrm{C}$, over the whole operating range.

On the other hand, Tello-Oquendo et al. (2016) conducted a comparison of two compressor technologies with vapor-injection, an SCVI and a two-stage reciprocating compressor (TSRC). The compressor performances were studied in a vapor-injection cycle with an economizer, using R-407C as refrigerant. The seasonal performances of both systems were estimated for an evaporating range between $-30{ }^{\circ} \mathrm{C}$ and $0{ }^{\circ} \mathrm{C}$ in cooling mode, and a condensing range between 40 ${ }^{\circ} \mathrm{C}$ and $70{ }^{\circ} \mathrm{C}$ in heating mode. The compressors comparison was conducted in terms of compressor efficiencies, COP, and heating capacity working in a wide range of operating conditions. This study gives a general idea about the application range of the studied compressors in cooling and heating applications and the differences in the compressor performance. Results showed that the SCVI presents better efficiency and COP when working with pressure ratios below 7.5, and the TSRC improves the COP when working with higher pressure ratios. Nevertheless, the catalog data of the TSRC were limited and it was not possible to predict the discharge temperature of this compressor. The TSRC model was based on efficiency curves and no comparison was made of the discharge temperature of the compressors.

Up to this point, based on the literature review, a systematic comparison between an SCVI and a TSSC has not been addressed. The vapor-injection in these two compressors is different. In the SCVI, the refrigerant injection is performed continuously in the same set of scrolls during the compression. Instead in the TSSC, the two compression stages are separated. The compressed refrigerant in the first stage is mixed with the injection refrigerant in a mixing chamber at constant pressure. The resulting mixture is then compressed in the second compression stage. 
In this context, questions about the advantages and disadvantages of compressor technologies available for two-stage systems, the correct sizing of the compressors, the optimum intermediate pressure are posed and these need to be understood in order to design heat pump systems working with high pressure ratios.

In order to answer to the questions posed above, the current paper addresses evaluation of the performance of an SCVI for heat pump applications (capacities above $5 \mathrm{~kW}$ ), working under extreme conditions, that is, at low evaporating temperatures or at high condensing temperatures. The analysis is based on a systematic comparison of the SCVI with a TSSC. In addition, in order to establish an objective comparison that contemplates an alternative two-stage compressor technology available in the market, a two-stage reciprocating compressor (TSRC) is included in the comparative analysis.

Semi-empirical models of the three compressors are used in the study. The models are adjusted with experimental data collected in the laboratory. To do so, an SCVI, a non-injected scroll compressor (SCNI) and a reciprocating compressor (RC) were characterized in a calorimetric test bench, using R-290 as refrigerant.

The optimum displacement ratio of the two-stage compressors (TSSC, TSRC) are defined taking into account two criteria, COP maximization, and discharge temperature minimization. Once the size of the compressors is defined, a systematic comparison of the performance of the three compressors (SCVI, TSRC, and TSSC) is conducted in terms of compressor efficiencies, COP, heating capacity, and discharge temperature, in a wide range of operating conditions. Finally, for a high-temperature water heating application $\left(>60{ }^{\circ} \mathrm{C}\right)$ and large water temperature lift $(20 \mathrm{~K})$, the intermediate pressure is optimized taking into account the temperature level and temperature lift of the secondary fluid in the condenser.

\section{Experimental setup}

Fig. 6.1 illustrates the scheme of the experimental setup used for testing the compressors. The installation consists of a calorimetric test bench with an additional injection line (gray line in Fig. 6.1) for testing the SCVI, as described by Tello-Oquendo et al. (2017).

The refrigerant conditions at compressor inlet (pressure and temperature) and outlet (pressure) are adjusted with PID control loops. The condensing pressure, evaporating pressure and the superheat at the compressor inlet are set acting on the flow rate of the water condenser, valves EEV-2, and resistors of the calorimeter, respectively.

To test the SCVI, the injection line is enabled by opening the ball valve $\mathrm{V}-1$. The electronic expansion valve EEV-1 regulates the intermediate pressure. The injection superheat is fixed with the water-glycol temperature through a heat exchanger. Electric resistors control the temperature of the water-glycol mixture in order to fix the injection superheat. To test the non-injected scroll compressor (SCNI) and the reciprocating compressor (RC), the injection line is disabled by closing the ball valve $\mathrm{V}-1$. 


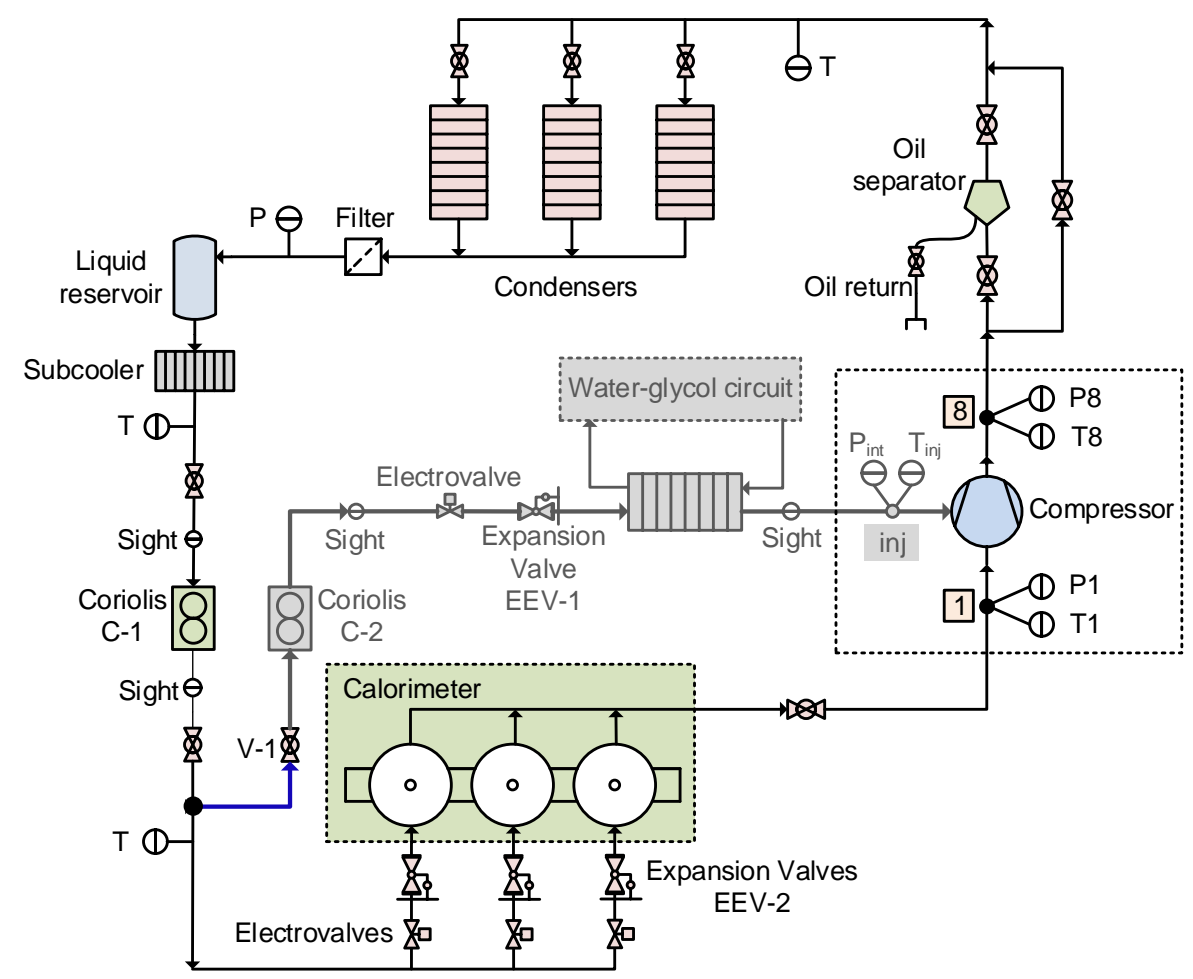

Fig. 0.1 Scheme of the calorimetric test bench.

The test bench is equipped with instruments for measuring the pressure and temperature in the suction and discharge of the compressor (points 1 and 8 in Fig. 6.1). The instrument accuracies of pressure transmitter (Fisher-Rosemount 3051) and temperature transmitter (RTD-PT 100) are $0.02 \%$ and $0.05{ }^{\circ} \mathrm{C}$, respectively.

The refrigerant mass flow rate is measured based on the European Standard EN 13771-1 (2016). Primary and confirming measurements were conducted simultaneously. The primary test procedure is the secondary refrigerant calorimeter method and the confirming test method is a Coriolis-type mass flow meter. The mass flow rate through the condenser was measured after the subcooler by using a Coriolis-type (Fisher-Rosemount Micro-Motion CMF025M), C-1 in Fig. 6.1. The injection mass flow rate was measured with a Coriolis-type mass flow meter with uncertainty of $\pm 0.025 \mathrm{~g} \mathrm{~s}^{-1}(\mathrm{C}-2)$. The evaporator mass flow rate is calculated as the difference between the condenser mass flow rate and the injection mass flow rate and is compared with the secondary refrigerant calorimeter based result.

The injection line was also equipped with a pressure transducer with a precision of $0.2 \%$, an RTD with a precision of $0.1 \mathrm{~K}$, and an electrovalve located before the expansion valve (EEV1). The compressor power input was measured with an electrical power meter with a precision of $0.1 \%$.

The swept volumes of the compressors are $17.28 \mathrm{~m}^{3} \mathrm{~h}^{-1}$ for the SCVI, $17.49 \mathrm{~m}^{3} \mathrm{~h}^{-1}$ for the SCNI and $20.71 \mathrm{~m}^{3} \mathrm{~h}^{-1}$ for the RC. All the compressors were tested with R-290 as refrigerant. For the SCVI, the laboratory tests were performed according to the following parameters: suction superheat of $10 \mathrm{~K}$, injection superheat of $5 \mathrm{~K}$ and $5 \mathrm{~K}$ of subcooling at the condenser outlet. For the SCNI and the RC, the parameters used were suction superheat of $10 \mathrm{~K}$ and subcooling at the condenser outlet of $5 \mathrm{~K}$. The test points were selected as a function of the compressor working envelope of the manufacturer and considering operating conditions for heating applications. Fig. 6.2 shows the working map of the compressors and the tested points for each compressor. 
Safety was a major concern during the design of the test facility. Specific procedures and standards regarding the handling and use of flammable gasses were taken into account (European Standard EN 378, 2017). The specific measures include the use of intrinsically safe electric material, specific propane sensors, the use of emergency switches and alarms and appropriate air renewal procedures to ensure no-critical concentrations in the case of leakage (European Standards: EN 60079-14, 2014; EN 60079-15, 2010; EN 60335-2-34, 2013; EN 60335-2-40, 2003).

a)

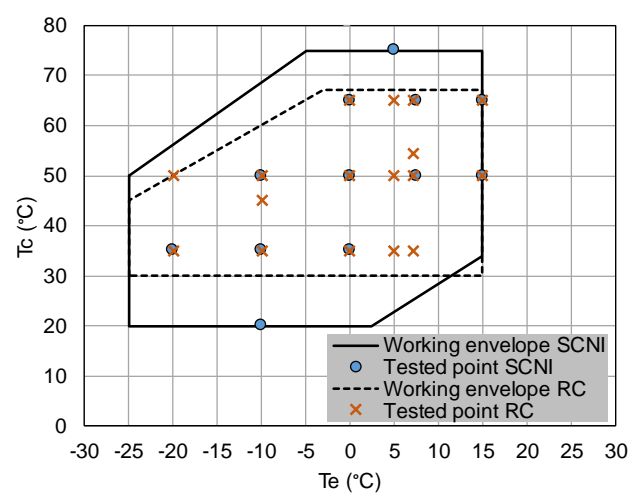

b)

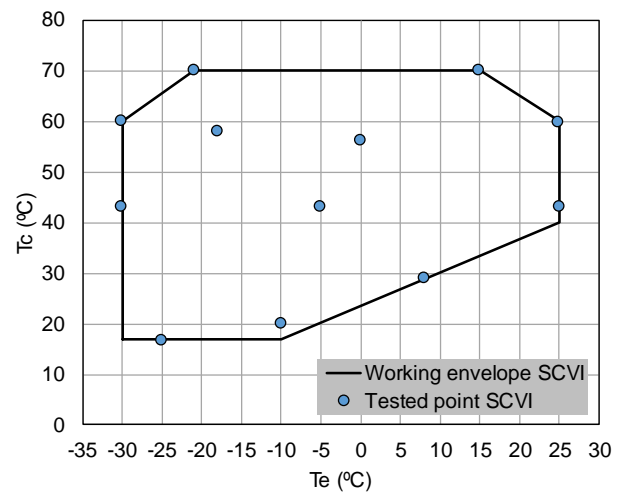

Fig. 0.2 Compressor working envelope and test points for the compressors working with R-290. a) SCNI and RC. b) SCVI.

\section{Methodology}

\subsection{Model development}

A thermodynamic model of the cycle is implemented to establish the parameters for the two-stage cycles with vapor-injection. Fig. 6.3 depicts a general schematic of the two-stage vapor compression cycle and the P-h diagram. The cycle uses an internal heat exchanger (economizer) in the injection mechanism.

The pressure levels of the system $\left(\mathrm{P}_{1}, \mathrm{P}_{4}, \mathrm{P}_{8}\right)$ are calculated as the saturation pressures of the dew temperatures at the evaporator, condenser, and injection, respectively. The pressures of points 5, 6, 7 and 9 are defined by introducing the assumption of null pressure drop in the lines and heat exchangers of the system. The enthalpies of points 7 and 9 are defined by introducing the assumption of isenthalpic expansion in the valves (see Fig. 6.3b).

The temperatures of points 1 and 5 and therefore their enthalpies are calculated using the input parameters of superheat and subcooling. 
a)

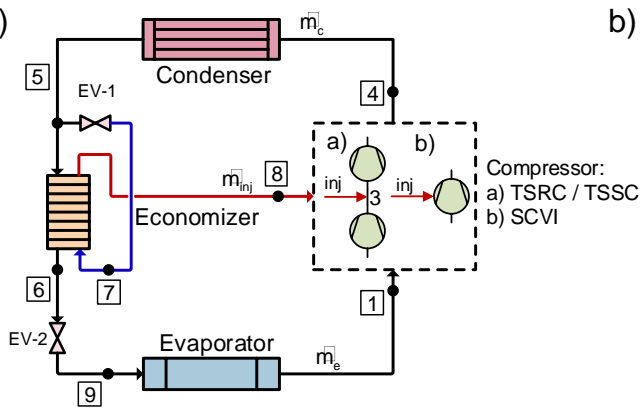

b)

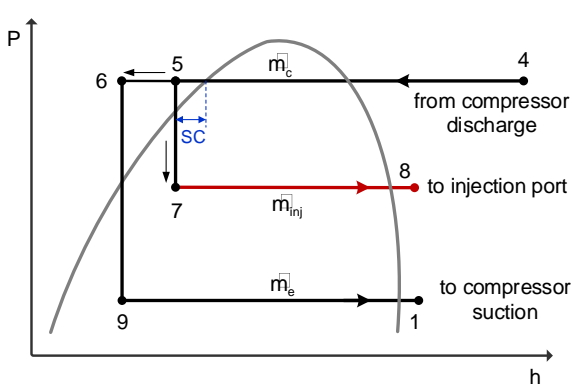

Fig. 0.3 Two-stage vapor compression cycle with vapor-injection. a) Schematic of the cycle with an economizer. b) P-h diagram.

The energy balance of Eq. (6.1) is met in the injection mechanism (economizer), and the condenser mass flow rate is defined by Eq. (6.2).

$$
\begin{gathered}
\dot{m}_{c} h_{5}=\dot{m}_{e} h_{6}+\dot{m}_{i n j} h_{8} \\
\dot{m}_{c}=\dot{m}_{e}+\dot{m}_{i n j}
\end{gathered}
$$

The model parameters are the dew evaporation and condensation temperature $\left(\mathrm{T}_{\mathrm{e}, \mathrm{d}}, \mathrm{T}_{\mathrm{c}, \mathrm{d}}\right)$, suction superheat, injection superheat and subcooling at the condenser outlet $\left(\mathrm{SH}, \mathrm{SH}_{\mathrm{inj}}, \mathrm{SC}\right)$. The compressor models described below calculate the evaporator mass flow rate, injection mass flow rate, compressor efficiencies, and discharge temperature of the compressor. The output variables calculated by the cycle model are heating capacity (Eq. (6.3)) and heating COP (Eq. (6.4)).

$$
\begin{gathered}
\dot{Q}_{h}=\dot{m}_{c}\left(h_{4}-h_{5}\right) \\
\operatorname{COP}_{h}=\frac{\dot{Q}_{h}}{\dot{E}}
\end{gathered}
$$

The injection superheat is fixed to $5 \mathrm{~K}$. The economizer size is fixed by setting a temperature approach in the economizer $\left(\mathrm{T}_{6}-\mathrm{T}_{7}\right.$ in Fig. $\left.6.3 \mathrm{a}\right)$ of $5 \mathrm{~K}$. For all operating points, this temperature approach is assumed constant (EN 12900, 2013).

Some cycle parameters are introduced for comparison purposes. $\mathrm{X}_{\text {inj }}$ is the injection ratio defined by Eq. (6.5). $\mathrm{C}_{\mathrm{o}}$ is the ratio between the actual intermediate pressure and the geometric mean of pressures defined by Eq. (6.6), and $D_{R}$ is the displacement ratio between the second and first stage of compression defined by Eq. (6.7).

$$
\begin{gathered}
X_{i n j}=\frac{\dot{m}_{i n j}}{\dot{m}_{c}} \\
C_{o}=\frac{P_{i n t}}{\sqrt{P_{e} P_{c}}} \\
D_{R}=\frac{\dot{V}_{s, H}}{\dot{V}_{s, L}}
\end{gathered}
$$




\section{Compressor models}

In the present study, three types of compressors are considered. A scroll compressor with vapor-injection (SCVI), a two-stage reciprocating compressor (TSRC) and a two-stage scroll compressor (TSSC). Fig. 6.4 illustrates the schematic of the compressor models. In the SCVI, the vapor-injection is performed at an intermediate pressure during the compression (see Fig. 6.4a). In the TSRC and the TSSC, the vapor-injection is performed after the first stage of compression in a mixing chamber at constant pressure (see point 3 in Fig. 6.4b). Point 3 is defined by Eq. (6.8), assuming a perfect adiabatic mixing between the injection mass flow rate at (point 8 ) and the evaporator mass flow rate (point 2).

$$
\dot{m}_{c} h_{3}=\dot{m}_{e} h_{2}+\dot{m}_{i n j} h_{i n j}
$$

a)

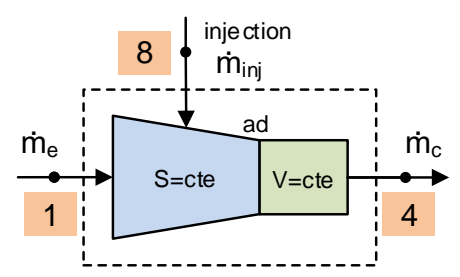

b)

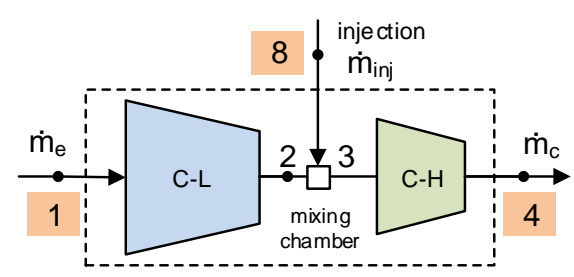

Fig. 0.4 Model scheme of the vapor-injection compressors. a) SCVI. b) TSRC and TSSC.

The TSSC is composed of two non-injected scroll compressors (SCNI) arranged in series, with vapor-injection between the two compression stages. To model each SCNI, a semi-empirical model of scroll compressor was implemented according to Tello-Oquendo et al. (2018b) and (2019). This model was validated experimentally and can reproduce the compressor efficiency and the volumetric efficiency with a deviation lower than $\pm 5 \%$ and $\pm 3 \%$, respectively. In addition, the model estimates the mass flow rate, the compressor power input and the discharge temperature with a deviation lower than $\pm 3 \%, \pm 5 \%$, and $\pm 3 \mathrm{~K}$, respectively (Tello-Oquendo et al., 2019). The model describes the ideal evolution of the refrigerant throughout the compressor and takes into account the main sources of losses in the compression process. The compressor losses are associated with a specific model parameter. These parameters of the model are fitted from experimental data.

Fig. 6.5 shows the refrigerant evolution through the compressor assumed in the model. The refrigerant enters the compressor at point 1 (suction) and leaves the compressor at point 2 (discharge). The refrigerant evolution through the scroll compressor is divided into the following sequence of effects:

(1-12): Isobaric vapor heating due to motor cooling and mechanical loss dissipation.

(12-13): Isobaric vapor heating due to the heat transferred from the hot side of the compressor (discharge plenum) to the inlet flow.

(13-14): Isenthalpic pressure loss in the suction port.

(14-14'): Isobaric vapor heating due to the leaks.

(14'-ad): Isentropic compression from the scrolls intake conditions (leaks appear in this part of the process) to the adapted pressure at the discharge port. 
(ad-15): Isochoric compression from the adapted pressure to the discharge pressure $\left(\mathrm{P}_{\mathrm{c}}\right)$ at the discharge plenum.

(15-16): Isenthalpic pressure loss in the discharge port.

(16-17): Isobaric vapor cooling due to the heat transferred to the suction side.

(17-2): Heat loss to ambient through the compressor shell.

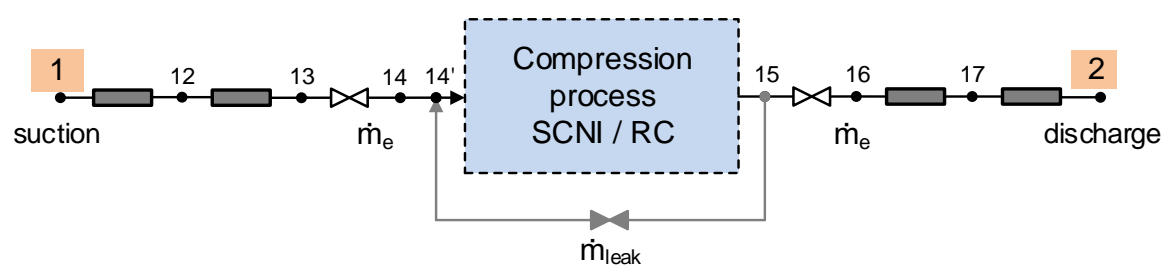

Fig. 0.5 Model scheme of the refrigerant evolution inside the compressor, for non-injected scroll compressors (SCNI) and reciprocating compressors (RC).

The reference for the overall compressor efficiency is given by an isentropic condition from the inlet to the outlet of the compressor $(2 \mathrm{~s})$. The volumetric efficiency and the overall compressor efficiency of the SCNI are calculated by Eqs. (6.9) and (6.10), respectively. Eq. (6.10) represents the ratio between the ideal isentropic power consumption and the real indicated work for the compressor.

$$
\begin{gathered}
\eta_{v}=\frac{\dot{m}_{e}}{\dot{V}_{s} \rho_{1}} \\
\eta_{c}=\frac{\dot{m}_{e}\left(h_{2 s}-h_{1}\right)}{\dot{E}}
\end{gathered}
$$

The mass flow rate is calculated with Eq. (6.11), where $\dot{V}_{S}$ is the swept volume of the compressor defined by the Eq. (6.12), $\rho_{1}$ is the density at the compressor inlet, and $n$ represent the compressor speed.

$$
\begin{gathered}
\dot{m}_{e}=\eta_{v} \dot{V}_{s} \rho_{1} \\
\dot{V}_{s}=n V_{s}
\end{gathered}
$$

Moreover, in order to define an overall compressor efficiency of the TSSC the Eq. (6.13) is defined, where $h_{4 s}$ represents the enthalpy at the discharge pressure of the high-stage compressor, considering an isentropic compression from the compressor inlet condition (point 3 in Fig. 6.4b).

$$
\eta_{c}=\frac{\dot{m}_{e}\left(h_{2 s}-h_{1}\right)+\dot{m}_{c}\left(h_{4 s}-h_{3}\right)}{\dot{E}_{L}+\dot{E}_{H}}
$$


The SCVI was modeled as proposed by Tello-Oquendo et al. (2019). This semi-empirical model describes the vapor-injection into scroll compressors by using an empirical correlation (Eq. (6.14)), which relates the injection ratio $\left(\dot{m}_{i n j} / \dot{m}_{e}\right)$ and the intermediate pressure ratio $\left(P_{\text {int }} / P_{e}\right)$, as described by Tello-Oquendo et al. (2017). The correlation (6.14) allows estimating the injection mass flow rate as a function of the intermediate pressure for a given evaporation pressure level. The coefficients A and B are obtained by linear regression, based on the experimental data of the SCVI.

$$
\frac{\dot{m}_{i n j}}{\dot{m}_{e}}=A+B \frac{P_{i n t}}{P_{e}}
$$

Fig. 6.6 depicts the evolution of the refrigerant assumed in the SCVI model in a P-h diagram. The complex process of refrigerant injection is simplified as instantaneous isobaric mixing at the intermediate pressure. Therefore, the model assumes that the compression process is composed of the following sequence of effects:

(14'-19): Isentropic compression from the scrolls intake conditions (leaks appear in this part of the process) to the intermediate pressure.

(19-10) Isobaric mixture of the suction mass flow rate $\left(\dot{\mathrm{m}}_{\mathrm{e}}\right)$ and the injection mass flow rate $\left(\dot{\mathrm{m}}_{\mathrm{inj}}\right)$ at the intermediate pressure.

(10-ad): Isentropic compression from the mixture conditions at the intermediate pressure to the adapted pressure at the discharge port.

(ad-5): Isochoric compression from the adapted pressure $\left(\mathrm{P}_{\mathrm{ad}}\right)$ to the discharge pressure $\left(\mathrm{P}_{\mathrm{c}}\right)$ at the discharge plenum.

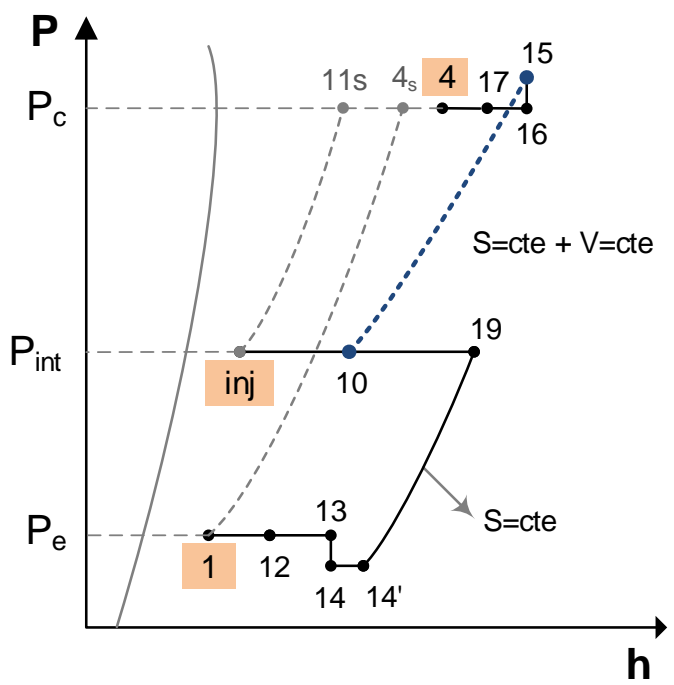

Fig. 0.6 P-h diagram of the refrigerant evolution inside the vapor-injection scroll compressor.

The reference for the compressor efficiency is given by an isentropic condition from the inlet to the outlet of the compressor $\left(4_{s}\right)$ for the suction mass flow rate, and by an isentropic 
condition from the injection (inj) to the discharge pressure $\left(11_{\mathrm{s}}\right)$ for the injected mass flow rate. The real conditions at the compressor outlet are indicated by state 4 in Fig. 6.6.

The volumetric efficiency of SCVI is defined by the Eq. (6.9). The overall compressor efficiency of SCVI is defined by Eq. (6.15), where $\mathrm{h}_{4 \mathrm{~s}}$ represents the enthalpy at the compressor discharge pressure considering an isentropic compression from the compressor inlet pressure (point 1 ), and $\mathrm{h}_{11 \mathrm{~s}}$ represents the enthalpy at the compressor discharge pressure considering an isentropic compression from the intermediate pressure (point inj).

$$
\eta_{c}=\frac{\dot{m}_{e}\left(h_{4 s}-h_{1}\right)+\dot{m}_{i n j}\left(h_{11 s}-h_{i n j}\right)}{\dot{E}}
$$

The described model of the SCVI was validated experimentally and can reproduce the compressor efficiency and the volumetric efficiency with a deviation lower than $\pm 5 \%$. In addition, the model estimates the mass flow rate, the injection mass flow rate, the compressor power input and the discharge temperature with a deviation lower than $\pm 2 \%, \pm 4 \%, \pm 5 \%$, and $\pm 4 \mathrm{~K}$, respectively (Tello-Oquendo et al., 2019).

On the other hand, the TSRC is composed of two reciprocating compressors (RC) arranged in series, with vapor-injection between the two compression stages (see Fig. 6.4b). In order to model the RC of each stage, a semi-empirical model was implemented according to Navarro-Peris et al. (2007a) and (2007b). The model was validated experimentally and can reproduce the compressor efficiency and the volumetric efficiency with a deviation lower than $\pm 4 \%$. In addition, the model estimates the mass flow rate, the compressor power input and the discharge temperature with a deviation lower than $\pm 2 \%, \pm 3 \%$, and $\pm 4 \mathrm{~K}$, respectively.

The compressor efficiency of each compressor stage is calculated by Eq. (6.10) and the volumetric efficiency is calculated by Eq. (6.9). Moreover, the overall compressor efficiency of the TSRC is calculated by Eq. (6.13). The thermophysical properties of the refrigerant at the different points are calculated with the NIST REFPROP database (Lemmon et al., 2010). All the models presented have been implemented using EES software (Klein and Alvarado, 2017).

\subsection{Optimization of the displacement ratio of the two-stage compressors}

When the systems are designed, the size of the compressors of each stage and, therefore, the displacement ratio $\left(D_{R}\right)$ must be defined. Generally, the $D_{R}$ is determined under the criterion of maximizing the COP of the cycle. However, two-stage compression is also applied to reduce the discharge temperature of the compressor. In the present work, the optimization of the $\mathrm{D}_{\mathrm{R}}$ is performed considering the two criteria, to maximize the COP and to minimize the discharge temperature.

The nominal point used in this study is $\mathrm{T}_{\mathrm{e}}=-15^{\circ} \mathrm{C}, \mathrm{T}_{\mathrm{c}}=50^{\circ} \mathrm{C}, \mathrm{SH}=5 \mathrm{~K}, \mathrm{SC}=5 \mathrm{~K}, \mathrm{SH}_{\text {inj }}=5 \mathrm{~K}$. The compressors sizes (swept volumes) are defined for having the same heating capacity as the SCVI at the nominal point. The refrigerant used is R-290.

The described models of the cycle and the compressors are implemented to simulate the system performance. The $D_{R}$ is varied from 0.50 to 0.70 , and it is analyzed in terms of the heating COP and discharge temperature. Results are discussed in section 6.4.1.

In addition, the optimum parameters of the ideal two-stage cycle and the ideal two-stage cycle with economizer are calculated. The ideal two-stage cycle is one that meets the conditions 
of perfect heat transfer in the injection mechanism $\left(\mathrm{DT}_{\mathrm{b}}=0\right.$ and $\left.\mathrm{DT}_{\mathrm{d}}=0\right)$, compressor efficiencies equal to unity and null heat loss. The variables $\mathrm{DT}_{\mathrm{b}}$ and $\mathrm{DT}_{\mathrm{d}}$ are defined by Eqs. (6.16) and (6.17), respectively, as described by Redón et al. (2014). These variables correspond to the thermodynamic limits of the second law in the injection mechanism of the cycle. The ideal condition of the cycle is reached when the economizer has an infinite heat transfer area.

$$
\begin{gathered}
D T_{d}=T_{5}-T_{8} \geq 0 \\
D T_{b}=T_{6}-T_{\text {int }, b} \geq 0
\end{gathered}
$$

The ideal two-stage cycle with economizer is one that has a defined size of the economizer. As commented before, the economizer size is fixed by setting the temperature approach of $5 \mathrm{~K}$ in the economizer.

\subsection{Comparison of the compressors' performance}

In real systems, the compressor can work in temperature conditions different from the nominal ones. In this section, the performance of the three compressors is calculated for several operating conditions considering heat pump applications working with high pressure ratios. These applications include heat pumps operating in cold regions (low evaporating temperatures), and heat pumps operating with high condensing temperatures such as high-temperature water heating applications and radiator heating systems.

Table 6.1 shows the operating conditions for the simulations. The compressor models were adjusted using the experimental data obtained in the calorimetric test bench. The swept volumes of the compressors defined in section 6.4.1 are used. The cycle has an economizer as injection mechanism (see Fig. 6.3a). The cycle parameters are $\mathrm{SH}=10 \mathrm{~K}, \mathrm{SH}_{\mathrm{inj}}=5 \mathrm{~K}, \mathrm{SC}=5 \mathrm{~K}, \mathrm{DT}_{\mathrm{b}}=5 \mathrm{~K}$. The compressors' performance are compared in section 6.4.2.

\begin{tabular}{|c|c|c|c|c|c|c|c|c|c|c|c|}
\hline \multirow{2}{*}{$\begin{array}{c}\mathbf{T}_{\mathbf{c}} \\
\left({ }^{\circ} \mathbf{C}\right)\end{array}$} & \multicolumn{11}{|c|}{$\mathbf{T}_{\mathrm{e}}\left({ }^{\circ} \mathbf{C}\right)$} \\
\hline & -30 & -25 & -20 & -15 & -10 & -5 & 0 & 5 & 10 & 15 & 20 \\
\hline 40 & & & & & & & & & & & \\
\hline 45 & & & & & & & & & & & \\
\hline 50 & & & & & & & & & & & \\
\hline 55 & & & & & & & & & & & \\
\hline 60 & & & & & & & & & & & \\
\hline 65 & & & & & & & & & & & \\
\hline 70 & & & & & & & & & & & \\
\hline 75 & & & & & & & & & & & \\
\hline 80 & & & & & & & & & & & \\
\hline
\end{tabular}

Table 0.1 Matrix of working points for the simulation of the two-stage cycle. Parameters: $\mathrm{SH}=10 \mathrm{~K}$,

\subsection{Optimization of the intermediate pressure for a water heating application}

In a two-stage cycle, when the compressor size and the injection mechanism are defined, the intermediate pressure is restricted to a determined value depending on the compressor design $\left(D_{R}\right)$ and the injection superheat. Generally, the intermediate pressure in a two-stage cycle is controlled by a thermostatic expansion valve, which maintains a fixed superheat in the injection 
line. When the injection superheat is fixed, the unique degree of freedom in the cycle for varying the intermediate pressure is the subcooling at the condenser outlet.

As established by Redón et al. (2014) and Tello-Oquendo et al. (2018a), in an ideal twostage cycle, the COP improves when subcooling is increased until the condenser outlet temperature matches the secondary fluid inlet temperature. Therefore, the subcooling is limited by the heat transfer in the condenser and by the temperature conditions of the secondary fluid. In this context, the subcooling is a determining factor in the calculation of optimum intermediate pressure in two-stage cycles.

This section addresses the optimization of the intermediate pressure for a water heating application. The simulated system is an air-to-water heat pump for high-temperature application and large temperature lift. The conditions of the secondary fluid (water) are inlet temperature of $45^{\circ} \mathrm{C}$, variable water flow rate and fixed water temperature lift of $20 \mathrm{~K}$. The refrigerant used is $\mathrm{R}-290$. The evaporating temperature is assumed constant $\left(-15{ }^{\circ} \mathrm{C}\right)$, and the condensing temperature is fixed by the secondary fluid (water) through an energy balance in the condenser. The parameters used in the simulation are suction superheat of $10 \mathrm{~K}$, injection superheat of $5 \mathrm{~K}$, and the temperature approach in the economizer of $5 \mathrm{~K}\left(\mathrm{DT}_{\mathrm{b}}\right)$. In order to show the influence of the subcooling on the optimum intermediate pressure and the COP, the subcooling was varied between $0 \mathrm{~K}$ to $28 \mathrm{~K}$. Results are discussed in section 6.4.3.

\section{Results and discussion}

Fig. 6.7 shows the compressor efficiencies of the three compressors tested in the calorimetric test bench. The experimental efficiencies are plotted as a function of the pressure ratio.

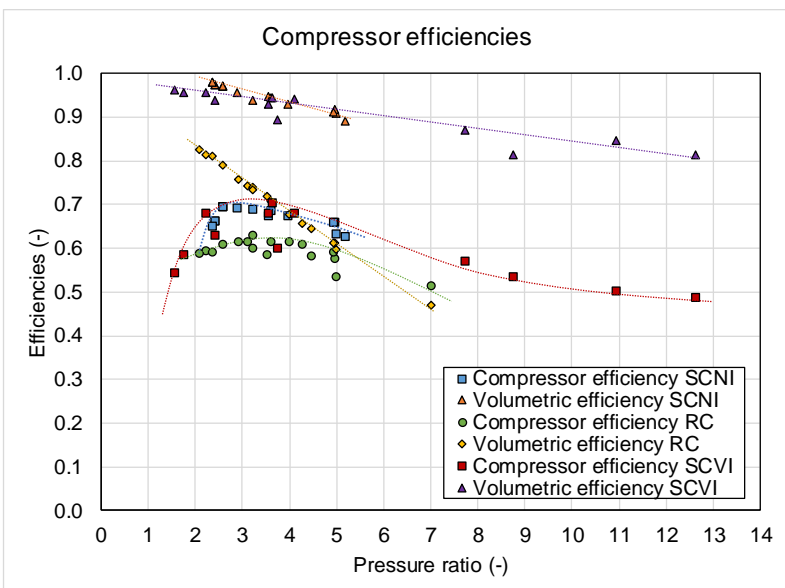

Fig. 0.7 Experimental efficiencies of the compressors. Refrigerant R-290.

The experimental data of the tested compressors are used to fit the parameters of the compressor models. Table 6.2 summarizes the parameters of the compressor models used in the present study. Once the compressor models were adjusted, they can be used to simulate the compressor performance of the SCVI, and of each compression stage of the TSRC and the TSSC.

Table 0.2 Model parameter fitted from experimental data of the compressors.

\begin{tabular}{l|c}
\hline Parameter & Compressor \\
\hline
\end{tabular}




\begin{tabular}{c|c|c|c|c}
\hline \multicolumn{2}{l|}{} & SCNI & RC & SCVI \\
\hline$\varepsilon$ & $(-)$ & 2.9 & - & 2.98 \\
$\mathrm{~K}_{1}$ & $\left(\mathrm{~K}^{-1}\right)$ & 0.928 & 0.9 & 0.92 \\
$\mathrm{~K}_{2}$ & $\left(\mathrm{~m}^{1 / 5}\right)$ & 0.085 & 0.9018 & 0.08 \\
$\mathrm{~K}_{3}$ & $\left(\mathrm{~m}^{-4}\right)$ & $1.369 \mathrm{E}+06$ & $3.833 \mathrm{E}+08$ & $4.058 \mathrm{E}+06$ \\
$\mathrm{~K}_{4}$ & $\left(\mathrm{~m}^{-4}\right)$ & $2.205 \mathrm{E}+08$ & $3.181 \mathrm{E}+09$ & $8.711 \mathrm{E}+08$ \\
$\mathrm{~K}_{5}$ & $(-)$ & 70.68 & 69.34 & 54.57 \\
$\mathrm{~K}_{6}$ & $(\mathrm{~J} \mathrm{~s})$ & 127 & 231.9 & 335.1 \\
$\eta_{\mathrm{el}}$ & $(-)$ & 0.88 & 0.859 & 0.864 \\
$\mathrm{UA}_{\mathrm{amb}}$ & $\left(\mathrm{W} \mathrm{K} \mathrm{K}^{-1}\right)$ & 0.55 & 0.75 & 0.81 \\
$\mathrm{~A}_{\text {leak }}$ & $\left(\mathrm{m}^{2}\right)$ & $1.146 \mathrm{E}-05$ & $1.084 \mathrm{E}-04$ & $8.525 \mathrm{E}-06$ \\
$\mathrm{~K}_{\mathrm{v}}$ & $(-)$ & - & 0.0548 & - \\
$\mathrm{A}$ & & - & - & -0.5928 \\
$\mathrm{~B}$ & & - & - & 0.4744 \\
\hline
\end{tabular}

\subsection{Optimization of the displacement ratio of the two-stage compressors}

Fig. 6.8 illustrates the variation of the heating COP and discharge temperature as a function of $\mathrm{D}_{R}$ of a two-stage cycle with vapor-injection, using TSRC and TSSC in the nominal point $\left(\mathrm{T}_{\mathrm{e}}=-\right.$ $15{ }^{\circ} \mathrm{C}, \mathrm{T}_{\mathrm{c}}=50{ }^{\circ} \mathrm{C}, \mathrm{SH}=5 \mathrm{~K}, \mathrm{SC}=5 \mathrm{~K}, \mathrm{SH}_{\mathrm{inj}}=5 \mathrm{~K}$ ). Fig. 6.8 a shows that the optimal point of the system, in terms of the $\mathrm{COP}$, is very close to the point that minimizes the discharge temperature. The $D_{R}$ that maximizes the COP is 0.57 and the $D_{R}$ that minimizes the discharge temperature is 0.6. This difference in $\mathrm{D}_{\mathrm{R}}$ represents a difference in the COP lower than $1 \%$, and a difference in the discharge temperatures below $1 \mathrm{~K}$. Therefore, the influence of the $\mathrm{D}_{\mathrm{R}}$ on the optimum COP is minimal. The same conclusions are verified in the case of the TSSC, as shown in Fig. 6.8b.

a)

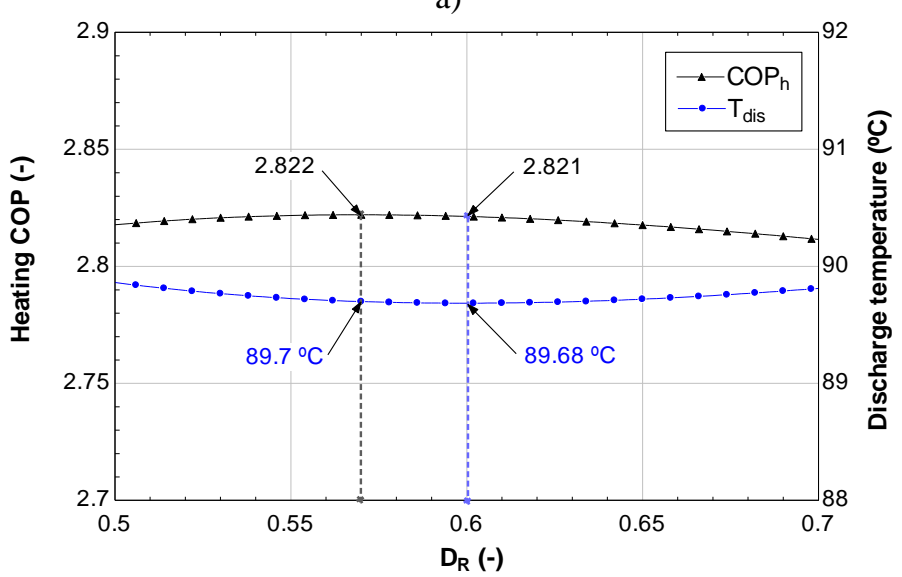

b) 


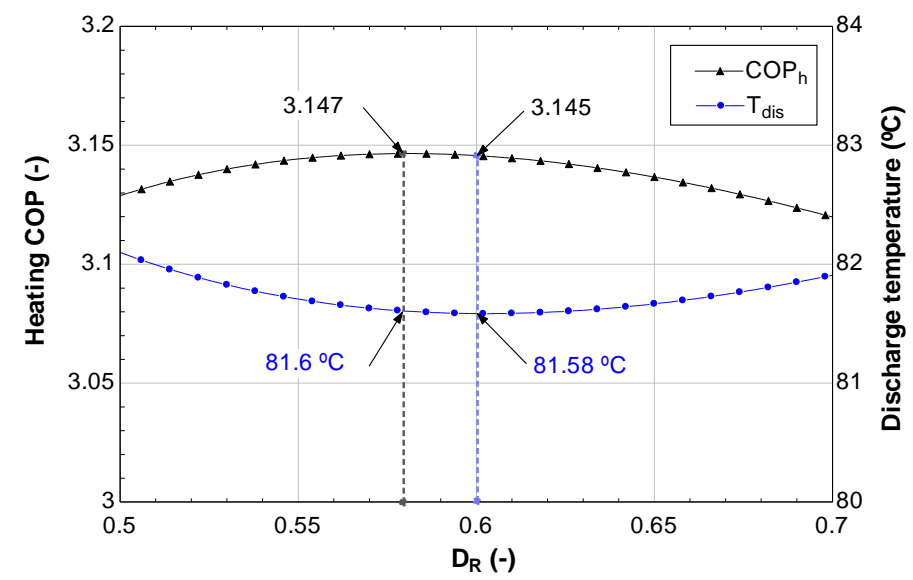

Fig. 0.8 Variation of the heating COP and discharge temperature as a function of the displacement ratio. Working point $\mathrm{T}_{\mathrm{e}}=-15^{\circ} \mathrm{C}, \mathrm{T}_{\mathrm{c}}=50^{\circ} \mathrm{C}, \mathrm{SH}=10 \mathrm{~K}, \mathrm{SH}_{\mathrm{inj}}=5 \mathrm{~K}, \mathrm{SC}=5 \mathrm{~K}$, refrigerant R-290. a) TSRC

b) TSSC

Table 6.3 shows the cycle parameters of the optimum operating conditions at the nominal point for all the compressors studied. The parameters of the ideal two-stage cycle and the ideal two-stage cycle with economizer are also shown.

Table 0.3 Optimum operation conditions for two-stage cycles. Working point $\mathrm{T}_{\mathrm{e}}=-15^{\circ} \mathrm{C}, \mathrm{T}_{\mathrm{c}}=50{ }^{\circ} \mathrm{C}$, $\mathrm{SH}=10 \mathrm{~K}, \mathrm{SH}_{\mathrm{inj}}=5 \mathrm{~K}, \mathrm{SC}=5 \mathrm{~K}$. Refrigerant R-290.

\begin{tabular}{|c|c|c|c|c|c|c|}
\hline \multirow[b]{2}{*}{ Parameter } & \multicolumn{6}{|c|}{ Cycle } \\
\hline & Ideal & $\begin{array}{c}\text { Ideal with } \\
\text { economizer }\end{array}$ & SCVI & TSRC & TSSC & $\begin{array}{c}\text { TSSC } \\
\text { Pint,SCVI }_{\text {int }}\end{array}$ \\
\hline $\mathrm{D}_{\mathrm{R}}(-)$ & 0.533 & 0.549 & - & 0.569 & 0.580 & 0.746 \\
\hline $\mathrm{COP}_{\mathrm{h}}(-)$ & 4.36 & 4.29 & 2.97 & 2.82 & 3.15 & 3.10 \\
\hline$\Delta \mathrm{COP}_{\mathrm{h}, \text { opt,eco }}(\%)$ & +1.63 & 0 & -30.77 & -34.27 & -26.57 & -27.74 \\
\hline$\dot{Q}_{h}(\mathrm{~kW})$ & 13.84 & 13.84 & 13.84 & 13.84 & 13.84 & 14.81 \\
\hline$\dot{Q}_{\text {eco }}(\mathrm{kW})$ & 2.63 & 2.40 & 2.45 & 2.04 & 2.18 & 2.72 \\
\hline$\dot{V}_{s, L}\left(\mathrm{~m}^{3} / \mathrm{h}\right)$ & 18.54 & 18.94 & 17.28 & 20.71 & 17.49 & 17.49 \\
\hline$\dot{V}_{s, H}\left(\mathrm{~m}^{3} / \mathrm{h}\right)$ & 9.9 & 10.40 & - & 11.78 & 10.15 & 13.05 \\
\hline $\mathrm{T}_{\text {dis }}\left({ }^{\circ} \mathrm{C}\right)$ & 69.51 & 64.85 & 88.27 & 89.70 & 81.60 & 82.24 \\
\hline $\mathrm{P}_{\text {int }}(\mathrm{kPa})$ & 740.31 & 706.70 & 576.11 & 712.29 & 698.89 & 576.19 \\
\hline$\dot{E}(\mathrm{~kW})$ & 3.17 & 3.23 & 4.67 & 4.91 & 4.40 & 4.78 \\
\hline$C_{o}(-)$ & 1.05 & 0.99 & 0.82 & 1.01 & 0.99 & 0.82 \\
\hline $\mathrm{X}_{\mathrm{inj}}(-)$ & 0.202 & 0.210 & 0.256 & 0.208 & 0.213 & 0.256 \\
\hline $\mathrm{SH}_{\mathrm{inj}}(\mathrm{K})$ & 29.57 & 5 & 5 & 5 & 5 & 5 \\
\hline $\mathrm{DT}_{\mathrm{b}}(\mathrm{K})$ & 0 & 5 & 5 & 5 & 5 & 5 \\
\hline $\mathrm{DT}_{\mathrm{d}}(\mathrm{K})$ & 0 & 26.27 & 33.49 & 25.98 & 26.67 & 33.48 \\
\hline$P_{r}(-)$ & 5.875 & 5.875 & 5.875 & 5.875 & 5.875 & 5.875 \\
\hline$\eta_{c}(-)$ & - & - & 0.601 & 0.586 & 0.677 & 0.672 \\
\hline$\eta_{v}(-)$ & - & - & 0.891 & - & 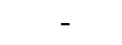 & - \\
\hline $\mathrm{P}_{\mathrm{r}, \mathrm{L}}(-)$ & 2.538 & 2.423 & - & 2.442 & 2.396 & 1.98 \\
\hline$\eta_{c, L}(-)$ & 1 & 1 & - & 0.557 & 0.656 & 0.588 \\
\hline$\eta_{v, L}(-)$ & 1 & 1 & - & 0.785 & 0.969 & 0.976 \\
\hline $\mathrm{P}_{\mathrm{r}, \mathrm{H}}(-)$ & 2.314 & 2.424 & - & 2.405 & 2.452 & 2.974 \\
\hline$\eta_{c, H}(-)$ & 1 & 1 & - & 0.610 & 0.693 & 0.716 \\
\hline$\eta_{v, H}(-)$ & 1 & 1 & - & 0.801 & 0.971 & 0.967 \\
\hline
\end{tabular}

In the first column of Table 6.3, the optimum parameters of the ideal two-stage cycle are shown. As commented before, the ideal cycle is one that considers unitary efficiencies of the 
compressors, a perfect heat transfer in the injection mechanism $\left(\mathrm{DT}_{\mathrm{b}}=0, \mathrm{DT}_{\mathrm{d}}=0\right)$ and null losses in the rest of the components. Under these conditions, the ideal cycle presents a COP of 4.36 and a displacement ratio of 0.533 .

In the second column of Table 6.3, the parameters of the ideal cycle with economizer are shown. In this case, by including in the system an economizer with a finite heat transfer area, the COP of the cycle is reduced by approximately $2 \%$. In addition, the $\mathrm{D}_{\mathrm{R}}$ increases to 0.549 .

The cycle parameters by using the compressors SCVI, TSRC, and TSSC are shown from the third column to the fifth column of Table 3. The compression irreversibilities produce a reduction of the cycle COP. Considering as a baseline the ideal cycle with an economizer, the COP decreases around $25 \%$ to $35 \%$ depending on the compressor technology, under nominal conditions. The TSSC compressor presents the lowest COP reduction, followed by the SCVI and finally the TSRC.

Comparing the three compressors, the cycle with TSSC achieves the highest COP, followed by the SCVI and finally the TSRC. This is due to the differences in the overall efficiencies of the compressors $\left(\eta_{c}\right)$. The SCVI has an efficiency comparable to that of the TSRC, but a lower efficiency than that of the TSSC.

In the two-stage compressors (TSRC, TSSC), each compression stage works with a lower compression ratio, which implies that the compressors are working closer to the optimum efficiency in each compression stage. On the contrary, the SCVI works with a higher pressure ratio to that of each compression stage in the TSRC and the TSSC, because the SCVI compress from the evaporating pressure to the condensing pressure. This fact has a significant impact on the compressor efficiency so that the SCVI is working outside the optimum efficiency range. As shown in Fig. 6.7, the maximum efficiency of the SCVI is found at a pressure ratio around 3, but the compression ratio in the nominal point is 5.87, and its efficiency decreases by $12 \%$ approximately.

The displacement ratio of the TSRC and the TSSC is around 0.57. However, the TSRC has a larger swept volume of the low-stage of compression $\left(\dot{V}_{s, L}\right)$, because of its lower volumetric efficiency.

With regard to the discharge temperature, the TSSC achieves a lower discharge temperature, while the other compressors have similar discharge temperatures but at least $8 \mathrm{~K}$ higher than the TSSC.

The intermediate pressure is another important parameter in two-stage cycles with vaporinjection. In the ideal cycle, the optimum intermediate pressure is greater than the geometric mean pressure $\left(\mathrm{C}_{\mathrm{o}}>1\right)$. In the ideal cycle with an economizer, the optimum intermediate pressure is almost equal to the geometric mean of pressures $\left(\mathrm{C}_{0}=1\right)$ in the nominal point. The SCVI works with lower intermediate pressure, however, the injection ratio is the highest of the three compressor technologies. In the SCVI, the amount of injected refrigerant is restricted by the size of the volutes and by the location of the injection port.

The two-stage compressors get closer to the geometric mean of pressures in the injection. This is due to the fact that in the design of the compressor, the volume of each compression stage can be optimized with more freedom. 


\subsection{Comparison of the compressors' performance in a wide range of operating conditions}

\subsubsection{Comparison of the compressor efficiencies}

Fig. 6.9a depicts the overall compressor efficiency as a function of the pressure ratio, for several condensing temperatures. The studied operating conditions correspond to pressure ratios greater than 3, where the vapor-injection technique results interesting. Under these conditions, the SCVI is working outside the optimum efficiency. The optimum efficiency of the SCVI could be achieved for pressure ratios around 3 (see Fig. 6.7), nevertheless, for higher pressure ratios the efficiency decreases rapidly due to the effects of under-compression, as shown in Fig. 6.9a.

The optimum efficiencies of the TSRC and TSSC are found for pressure ratios around 5.5 and 7.5, respectively. For higher pressure ratios, the efficiencies decrease smoothly, getting to work with a wide range of pressures. The efficiency curves of the two-stage compressors (TSRC and TSSC) have less slope than that of the SCVI. This is owed to the differences in the compression process. As mentioned before, the SCVI works with a higher pressure ratio than each stage compressors of the TSRC and the TSSC. The SCVI compress from the evaporating pressure to the condensing pressure. Nevertheless, in the two-stage compressors, each compression stage works with a lower compression ratio. Hence, they are working closer to their optimum efficiency.

The SCVI improves the efficiency for pressure ratios up to 4.5 and 6.5 compared with the TSSC and TSRC, respectively. For example, for $\mathrm{P}_{\mathrm{r}}=3.3$ at the point $\left(10{ }^{\circ} \mathrm{C}, 60{ }^{\circ} \mathrm{C}\right)$, the $\mathrm{SCVI}$ efficiency improved by $21 \%$ and $15 \%$ compared with the efficiencies of the TSRC and the TSSC, respectively. 
a)

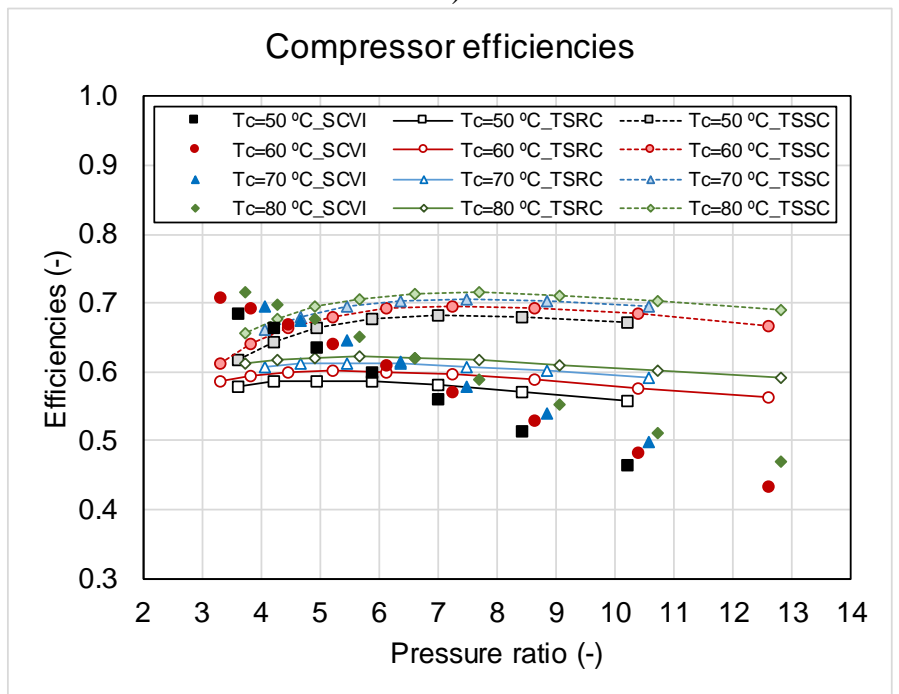

b)

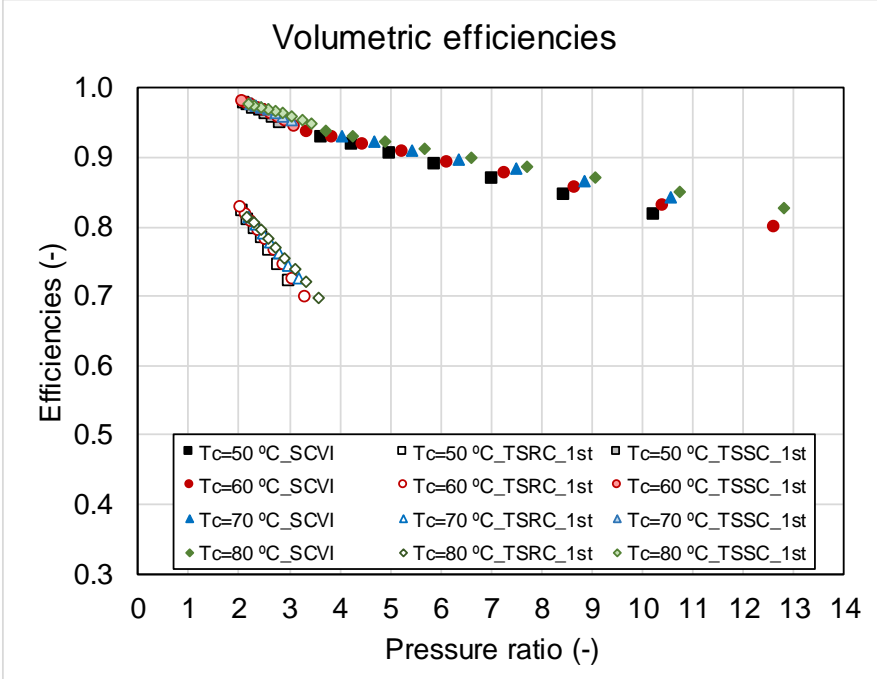

Fig. 0.9 a) Compressor efficiency as a function of pressure ratio. b) Volumetric efficiencies as a function of pressure ratio at several condensing temperatures.

The TSSC improves the efficiency for all the studied range of pressures compared with the TSRC and improves the efficiency for pressure ratios from 4.5 compared with the SCVI. For example, for $\mathrm{P}_{\mathrm{r}}=10.6$ at the point $\left(-20^{\circ} \mathrm{C}, 70^{\circ} \mathrm{C}\right)$, the TSSC efficiency improved by $39 \%$ and $37 \%$ compared with the efficiencies of the SCVI and the TSRC, respectively.

Fig. 6.9b depicts the volumetric efficiency as a function of the pressure ratio for several condensing temperatures. For comparison purposes, the represented curves for the two-stage compressors correspond to the first stage of compression, since the volumetric efficiency is related to the evaporator mass flow rate.

The SCVI and TSSC present curves of volumetric efficiency with less slope. These scroll compressors present high volumetric efficiency, above 0.8 for any operating point. This is owed to the absence of re-expansion volumes, the continuous-flow process, and the good axial and radial compliance of the scroll members (ASHRAE Handbook, 2008). Hence, the scroll compressors have better volumetric efficiency than the TSRC for any pressure ratios and can achieve improvements of $18 \%$ and $34 \%$ for pressure ratios of 2.0 and 3.3, respectively. 
The TSRC presents volumetric efficiency curves with a higher slope. For the first stage of compression, the volumetric efficiency drops to 0.7 for a pressure ratio of 3.3.

\subsubsection{Comparison of the heating capacity}

Fig. 6.10a illustrates the heating capacity as a function of the evaporating temperature for several condensing temperatures. The heating capacities of the compressors are similar since the compressor size of the two-stage compressors were optimized to have the same heating capacity than the SCVI at the nominal point. Nevertheless, for working conditions different from the nominal one, some differences can be observed.

The SCVI presents curves of capacity with less slope compared with the curves of the twostage compressors. The heating capacity of the SCVI is slightly higher for low evaporating temperatures (less than $0{ }^{\circ} \mathrm{C}$ ); this is owed to the differences in the volumetric efficiency of the compressors shown in Fig. 6.9b, and because the SCVI has a larger injection ratio, as shown in Fig. 6.10b. For higher evaporating temperatures, like $20{ }^{\circ} \mathrm{C}$, the TSRC improves the heating capacity by $1.5 \%$ and $3.6 \%$ compared with TSSC and SCVI, respectively (condensing at $80{ }^{\circ} \mathrm{C}$ ).

The differences in the injection ratio of the three compressor technologies are owed to the SCVI compresses the refrigerant in a single stage with refrigerant injection at an intermediate point during the compression. The amount of injected refrigerant depends on the location and size of the injection ports. While the two-stage compressors have two well-defined stages of compression in separated pistons or scrolls, and the amount of injected refrigerant depends on the size of the high stage compressor.

a)

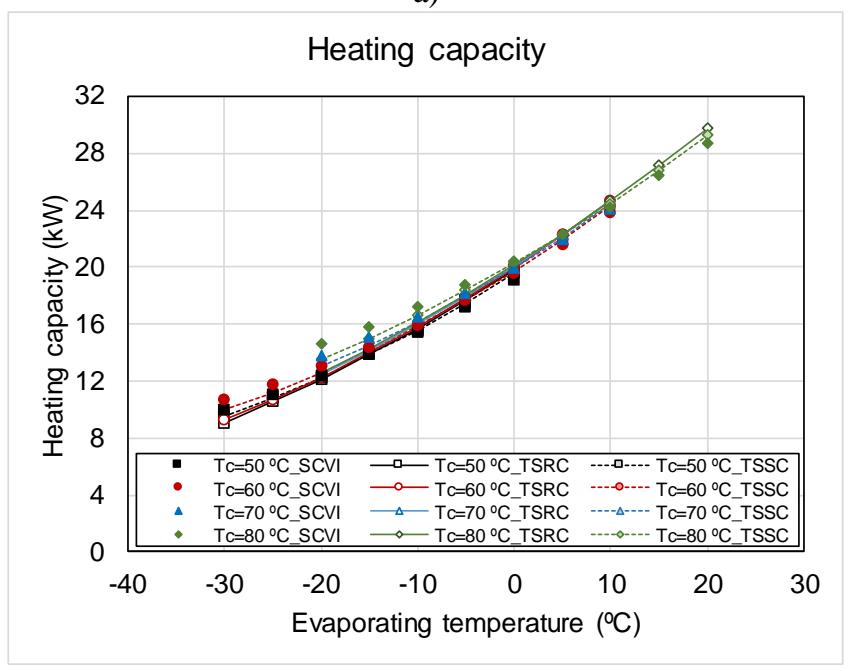

b) 


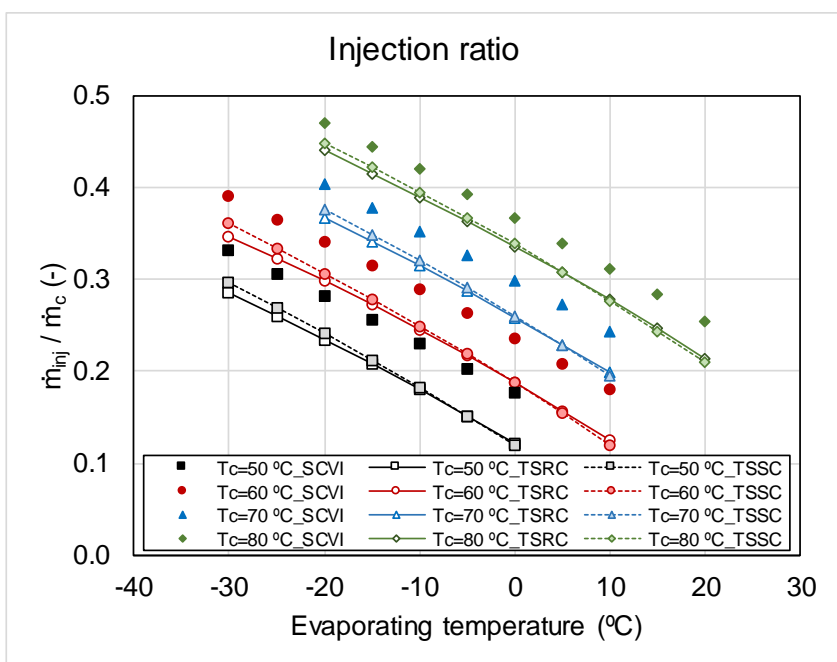

Fig. 0.10 a) Heating capacity as a function of evaporating temperature. b) Injection ratio as a function of evaporating temperature at several condensing temperatures.

\subsubsection{Comparison of the heating COP}

Fig. 6.11 illustrates the heating COP according to the evaporating temperature at several condensing temperatures. The system with SCVI presents curves of COP with a higher slope. Therefore, the SCVI improves the COP compared with the TSSC for working conditions corresponding to pressure ratios above 5. This is due to the higher compressor efficiency of the SCVI in these conditions (see Fig. 6.9a) and the differences in the economizer capacity (see Fig. $6.12)$.

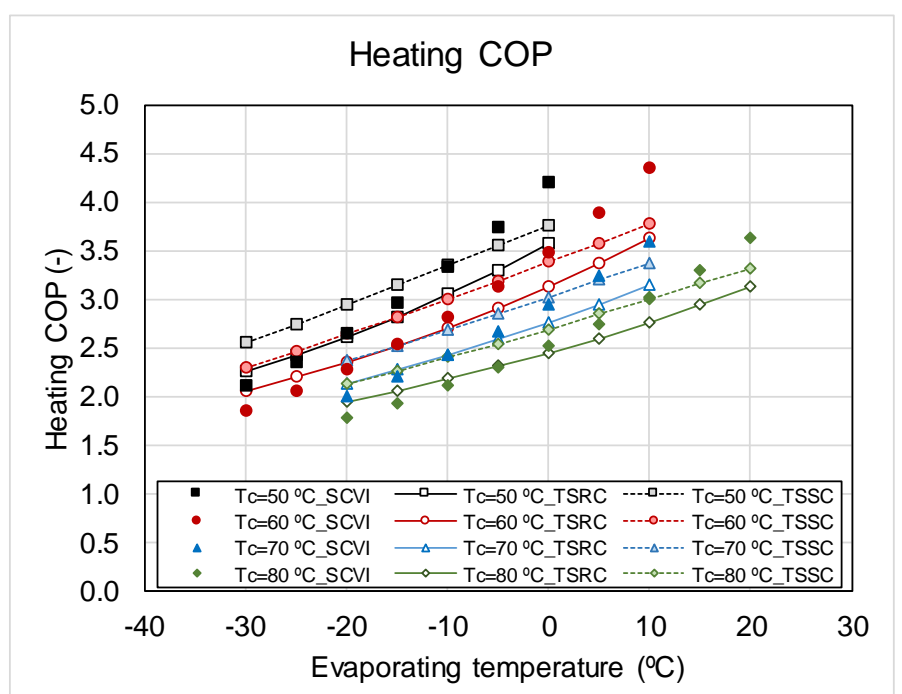

Fig. 0.11 Heating COP as a function of the evaporating temperature at several condensing temperatures.

The systems with two-stage compressors present curves with less slope, which implies a better performance when the compressors work with lower evaporating temperatures. Nevertheless, the TSSC improves the COP in all working conditions compared with TSRC, mainly owed to the higher compressor efficiency of the TSSC (see Fig. 6.9a).

Under extreme working conditions (pressure ratios above 7.5), the TSSC presents a better COP than the other two compressors. For example, at the point $\left(-20{ }^{\circ} \mathrm{C}, 50^{\circ} \mathrm{C}\right)$, the system with 
TSSC improves the COP by $11.3 \%$ and $12.5 \%$ compared with SCVI and TSRC, respectively. For higher condensing temperatures such as $80{ }^{\circ} \mathrm{C}$, the COP of the TSSC is improved by $19.7 \%$ and 9.4\% compared with SCVI and TSRC, respectively.

In the same point $\left(-20{ }^{\circ} \mathrm{C}, 50{ }^{\circ} \mathrm{C}\right)$, the system with SCVI improves the COP by $1.1 \%$ compared with TSRC, but for higher condensing temperatures, such as $80^{\circ} \mathrm{C}$, the COP is lower than TSRC by $9.5 \%$. This COP difference is owed to the SCVI efficiency decreases for pressure ratios higher than 6.5 .

When the compressors work with higher evaporating temperatures like $0{ }^{\circ} \mathrm{C}$ (pressure ratios below 7), the system with SCVI improves the COP up to $11.6 \%$ and $17.7 \%$ compared with TSSC and TSRC, respectively (condensing at $50{ }^{\circ} \mathrm{C}$ ). However, for higher condensing temperatures, such as $80{ }^{\circ} \mathrm{C}$, the system with TSSC improves the COP by $7.1 \%$ and $9.9 \%$ compared with SCVI and TSRC, respectively.

The results suggest that the SCVI can be used in heat pumps and air conditioning systems working under moderate temperature conditions and pressure ratios below 6.5 ; the TSRC can be used in water heating systems in cold climates and high pressure ratios (above 6.5). The TSSC can be used in water heating systems in cold climates but under a wider range of pressure ratios (above 4.5).

It is important to note that the results obtained in the present study for TSSC and TSRC correspond to compressors with independent compression stages. This methodology was adopted in order to establish a fair comparison between two-stage compressors, since, in the case of scroll technology, no compressors available on the market that carry the two compression stages in the same housing have been found so far. However, the conclusions obtained in the present study for the TSRC, do not differ from the conclusions obtained for two-stage compressors where the two compressors are in the same shell and are driven by the same shaft (Tello Oquendo et al., 2016). This fact leads us to think that the conclusions obtained in the present work may be valid for twostage scroll compressors with the two stages inside the same shell.

In the present study, the economizer capacity is a qualitative parameter, which is related with the size of the internal heat exchanger (economizer) and the capacity available to exchange heat to the injected refrigerant in the system. Fig. 6.12 illustrates the economizer capacity for the three compressors as a function of the evaporating temperature.

Fig. 6.12 shows that the economizer capacity curves of the two-stage compressors have less slope than the curves of the SCVI. The SCVI presents higher economizer capacity than the TSRC in all working conditions. For low evaporation temperatures (below $-10^{\circ} \mathrm{C}$ ), which involve high-pressure ratios (above 6.5), the TSSC system presents higher economizer capacity than the SCVI system. 


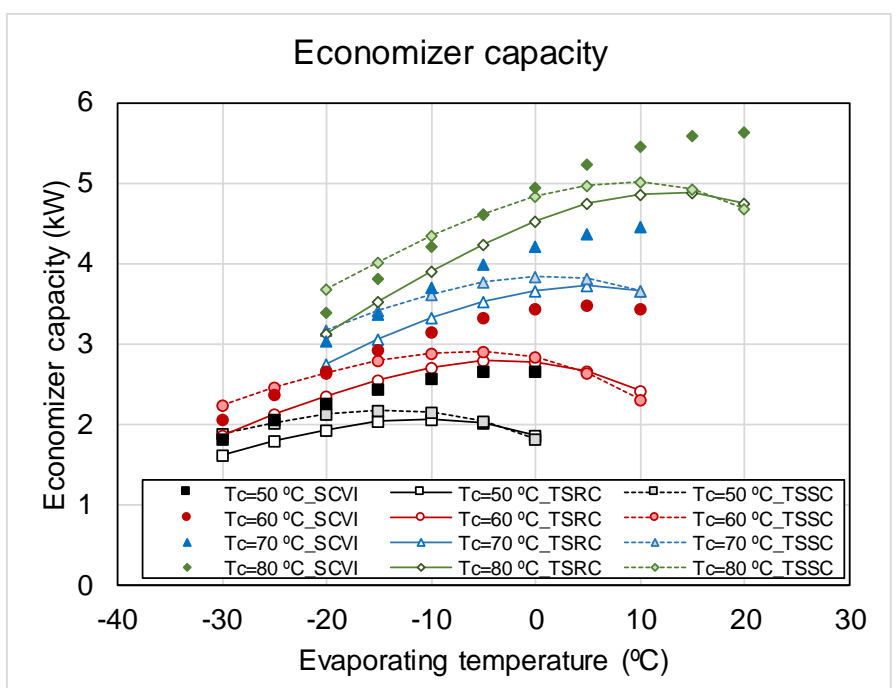

Fig. 0.12 Economizer capacity as a function of the evaporating temperature at several condensing temperatures.

Comparing the TSSC and TSRC compressors, Fig. 6.12 shows that the economizer capacity of TSSC is greater than that of the TSRC as the evaporating temperature decreases and the condensing temperature increases. This effect explains the differences in the heating capacity of Fig. 6.10a, and the differences in the injection ratio of Fig. 6.10b.

\subsubsection{Comparison of the discharge temperature}

Discharge temperature is an important compressor parameter due to the possibility of estimating the working limits of the compressors taking into account the possible oil degradation at high temperatures. Hence, the extension of the working map of compressors with vaporinjection technique can be estimated.

a)

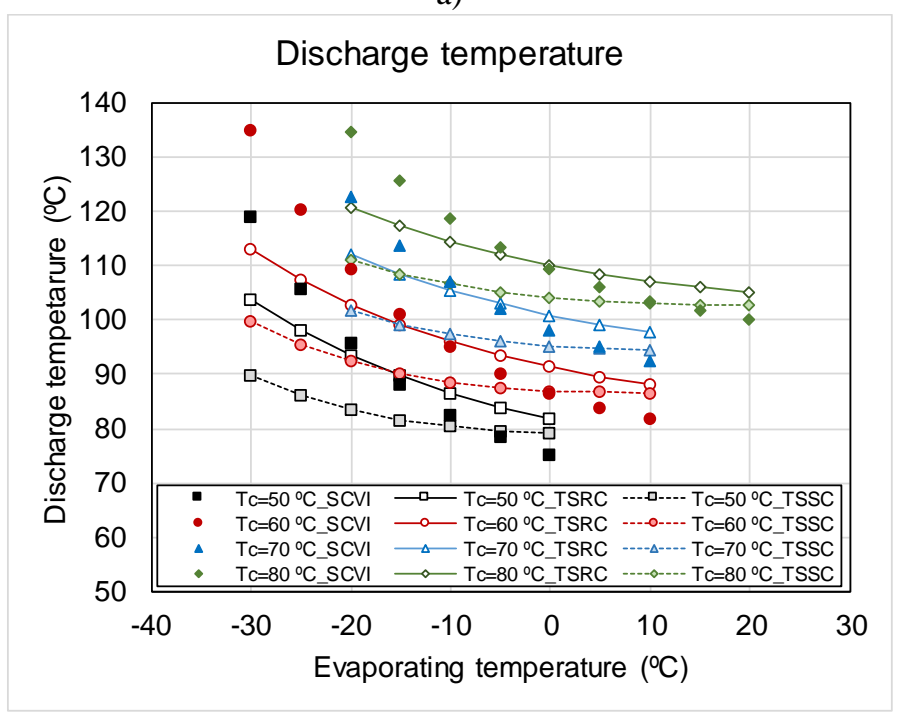

b) 


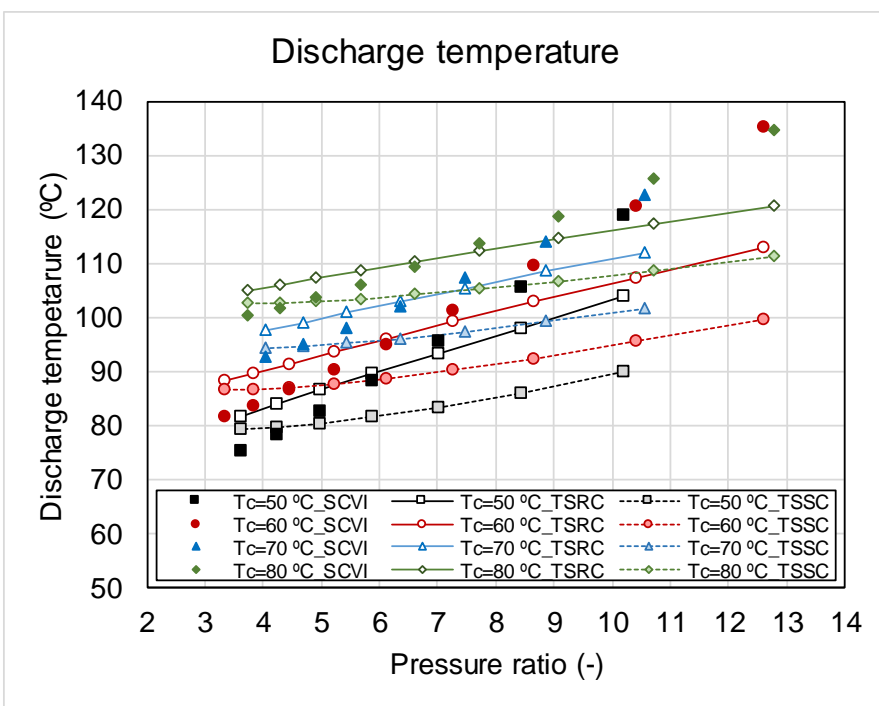

Fig. 0.13 a) Discharge temperature as a function of the evaporating temperature. b) Discharge temperature as a function of the pressure ratio at several condensing temperatures.

Fig. 6.13a shows the discharge temperature of the compressors as a function of the evaporating temperature for several condensing temperatures. The discharge temperature curves of the two-stage compressors have less slope than the curves of the SCVI. This means that the two-stage compressors can extend more the working map for lower evaporating temperatures than the SCVI.

Comparing the SCVI with the two-stage compressors, Fig. 6.13b shows that the SCVI achieves a lower discharge temperature than the TSSC for low pressure ratios (below 4.8). For pressure ratios lower than 7, the SCVI achieves lower discharge temperatures than the TSRC.

Regarding the two-stage compressors, the TSSC achieves a lower discharge temperature than the TSRC for all the working conditions considered in the study. This is owed to the higher compressor efficiency of the TSSC. For extreme conditions $\left(\mathrm{P}_{\mathrm{r}}>4.8\right)$, the TSSC presents a lower discharge temperature than the SCVI.

If the discharge temperature is limited to $120{ }^{\circ} \mathrm{C}$, taking into account the possible degradation of the lubricating oil, the working map of the SCVI is more restricted than that of the two-stage compressors. The SCVI could work evaporating up to $-30{ }^{\circ} \mathrm{C},-25{ }^{\circ} \mathrm{C},-18{ }^{\circ} \mathrm{C}$ and -12 ${ }^{\circ} \mathrm{C}$, condensing at $50{ }^{\circ} \mathrm{C}, 60^{\circ} \mathrm{C}, 70{ }^{\circ} \mathrm{C}$ and $80{ }^{\circ} \mathrm{C}$, respectively. This corresponds to compression ratios less than 10.5 for condensing temperatures between $50{ }^{\circ} \mathrm{C}$ and $70{ }^{\circ} \mathrm{C}$, and compression ratios less than 9.5 for a condensing temperature of $80{ }^{\circ} \mathrm{C}$.

Since the curves of the two-stage compressors have less slope, they can work in a wider range of working conditions. However, for very high condensation temperatures $\left(80{ }^{\circ} \mathrm{C}\right)$, the TSRC could work evaporating up to $-18^{\circ} \mathrm{C}\left(\mathrm{P}_{\mathrm{r}}=12.5\right)$.

The differences in the discharge temperature between the SCVI and the two-stage compressors is due to the fact that the compression in the SCVI is more like compression in one stage, while in the other compressors there are well-defined compression stages. This leads us to think that the two-stage compression with vapor-injection, independently of the compressor technology, is more effective in the reduction of the discharge temperature than the compressors with vapor-injection (SCVI). Therefore, two-stage compressors can be used in applications such as high-temperature water heating up to $80^{\circ} \mathrm{C}$. 
It is important to note that the results of the discharge temperature shown in this work were obtained with the compressors working with R-290 as refrigerant. Generally, the discharge temperatures obtained with this refrigerant are moderate compared with those obtained using other refrigerants such as R-410A, R-407C or R-134a. Therefore, the working map of the SCVI can be further limited when the system uses a different type of refrigerant. In that case, a twostage scroll or reciprocating compressor would be favorable to reduce the discharge temperature working with high pressure ratios.

\subsection{Comparison of the optimal intermediate pressure for a water heating application}

This section presents the optimization of the intermediate pressure for the high-temperature water heating application with large temperature lift, described in section $6.3 .4\left(\mathrm{~T}_{\mathrm{w}, \mathrm{in}}=45^{\circ} \mathrm{C}\right.$, $\Delta \mathrm{T}_{\mathrm{w}}=20 \mathrm{~K}$ ). In this study, the optimized compressors described in section 6.4 .1 are used.

Fig. 6.14a shows that the optimum point is achieved when the $\mathrm{SC}=14.6 \mathrm{~K}$ for the cycle with SCVI, SC $=14.9 \mathrm{~K}$ for the cycle with TSRC and SC=15.8 K for the cycle with TSSC. Overall, for the studied application, the optimum subcooling is around $15 \mathrm{~K}$ independently of the compressor technology. However, differences in the optimum COP of the cycle and in the correspondent intermediate pressure can be observed. The TSSC cycle improves the COP by $11.9 \%$ and $11.2 \%$ compared with SCVI and TSRC, respectively. The optimum COP of the cycle with SCVI and TSRC are almost equal.

The optimum intermediate pressure is lower than the geometric mean of pressures (red line in Fig. 6.14a) for all the compressors studied. The optimum intermediate pressure is 5.5\%, 9.9\%, and $26.5 \%$ lower than the geometric mean of pressures for TSRC, TSSC, and SCVI, respectively.

Fig. 6.14b shows the influence of the subcooling on the heating capacity. For all the compressors, the heating capacity increases mainly owed to the increase of the enthalpy difference in the condenser for larger values of subcooling. The heating capacity of the SCVI working with the optimum subcooling is $2.4 \%$ greater than the TSSC, and $3.6 \%$ greater than the TSRC.

Regarding the discharge temperatures, the studied compressors present some differences. In the optimum point, the SCVI presents the highest discharge temperature, which is $3.7 \mathrm{~K}$ and 12.3 K higher than discharge temperatures of TSRC and TSSC, respectively. The temperature difference increases as the subcooling increases.

These results suggest that the subcooling is an important parameter to find the optimum intermediate pressure for heat pump applications with large temperature lift of the secondary fluid. The TSSC presents higher COP in the optimum conditions. This compressor technology is more effective for reducing the discharge temperature. 


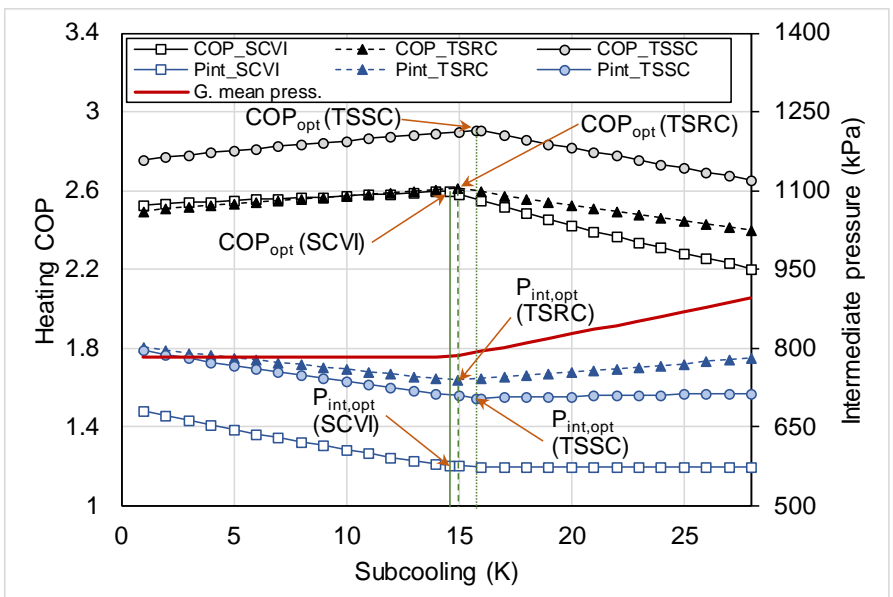

b)

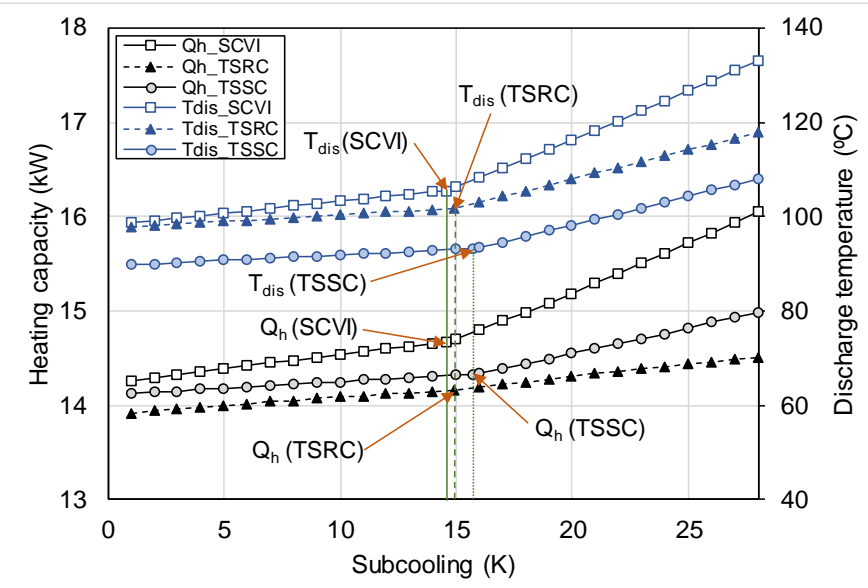

Fig. 0.14 a) Influence of the SC on the intermediate pressure and heating COP. b) Influence of the SC on the heating capacity and discharge temperature.

\subsection{Performance comparison of the SCVI and the TSSC working with the same intermediate pressure}

Up to this point in the analysis, the performance of the compressors has been compared when the two-stage compressors have the same heating capacity as the SCVI at the nominal point, and the $D_{R}$ is optimized to maximize the COP. Nevertheless, as observed in Table 6.3, the $P_{\text {int }}$ of the SCVI is lower than those corresponding to the two-stage compressors. The $\mathrm{P}_{\text {int }}$ depends on the design of the SCVI, the size of the scroll wraps and the location of the injection port. In the case of the TSSC, the compressors size of each stage can be defined independently. In this context, it is proposed to compare the performance of the TSSC working with the same $\mathrm{P}_{\text {int }}$ than the SCVI at the nominal point. For this, the displacement ratio of the TSSC has been changed so that its $\mathrm{P}_{\text {int }}$ coincides that of the SCVI. To change the $\mathrm{D}_{\mathrm{R}}$, only the swept volume of the high-stage compressor has been modified.

The last column of Table 6.3 shows the parameters of the cycle using the TSSC operating at the same $\mathrm{P}_{\text {int }}$ as the SCVI. The $\mathrm{D}_{\mathrm{R}}$ of the TSSC was increased to 0.746 since the swept volume of the second stage is $28.6 \%$ larger. This change in the design of the TSSC makes that the compressor works out of the optimum of COP. However, the percentage of decrease is $1.59 \%$ with respect to the optimum COP, and the compressor efficiency decreases by $0.74 \%$. 
The most interesting result is the variation of the heating capacity. With the new $D_{R}$, the TSSC presents an increase of 7\% with respect to the optimum design. This increase of capacity is explained by the increase in the injection mass flow rate and thus the economizer capacity. On the other hand, the discharge temperature increases slightly, less than $1 \mathrm{~K}$.

Comparing the results of the new TSSC design with the SCVI, it is observed that the TSSC achieves a higher heating capacity $(+7 \%)$; the overall compressor efficiency $\left(\eta_{c}\right)$ is $11.8 \%$ higher than that of the SCVI and achieves a $4.4 \%$ higher COP. The discharge temperature of the TSSC is $7 \mathrm{~K}$ lower, and the economizer capacity is $11 \%$ higher than that of the SCVI.

Moreover, the performance of the new TSSC was calculated for a wide range of operating conditions. The results are compared with the performance of the SCVI working in the same conditions. The parameters of the two compressors are shown in Fig. 6.15.

Fig. 6.15a shows that the TSSC achieves a higher heating capacity than the SCVI. The difference becomes larger when the compressors work at high evaporation temperatures. However, the curves of the SCVI have less slope, so that for low evaporation temperatures, the heating capacity of the SCVI is slightly lower than that of the TSSC.

As commented before, the higher heating capacity of the TSSC manifests in a greater economizer capacity as shown in Fig. 6.15b. The difference in economizer capacity becomes more noticeable for high condensing temperatures.

a)

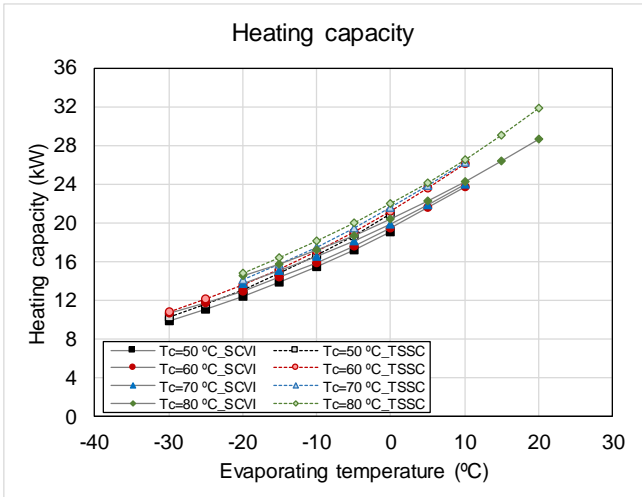

c)

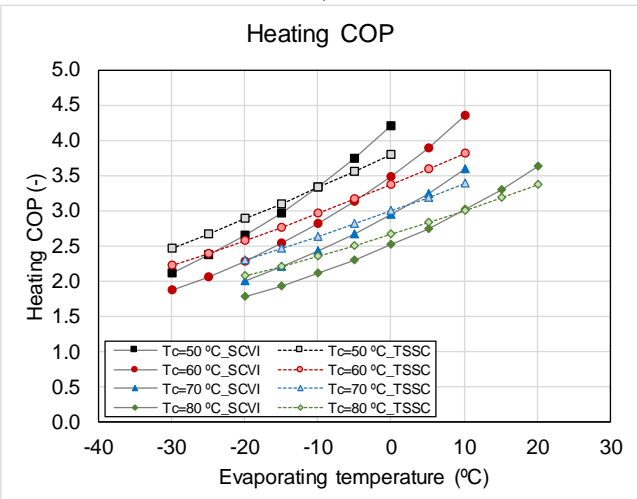

b)

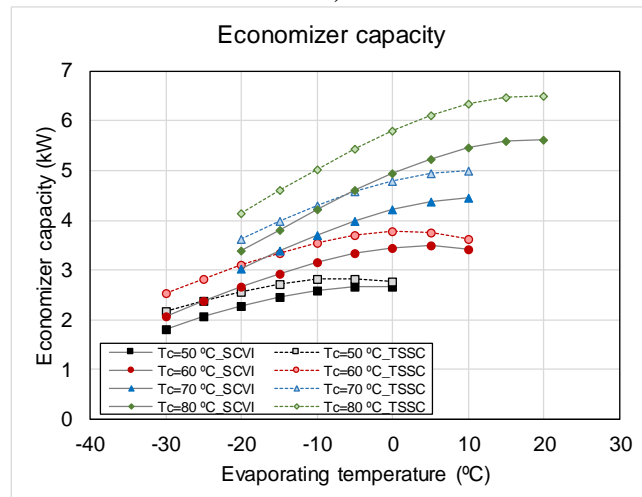

d)

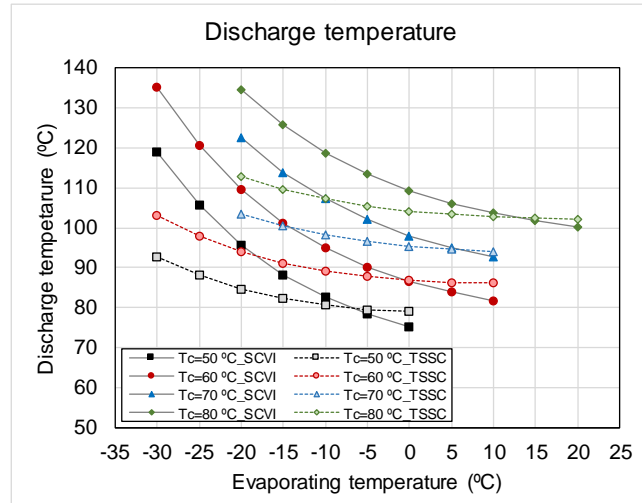

Fig. 0.15 Comparison of the performance of TSSC and SCVI. a) Heating capacity. b) Economizer capacity. c) Heating COP. d) Discharge temperature. 
Regarding the heating COP and the discharge temperature (Figs. $6.15 \mathrm{c}$ and $6.15 \mathrm{~d}$ ), the trends are similar to those obtained with the optimum design of the TSSC shown in Figs. 6.11 and 6.13, respectively. As it was expected, the only difference is that the COP of the TSSC is slightly lower and the discharge temperature is slightly higher than previously obtained values.

The results of the SCVI suggest that the compressor design allows keeping flatter curves of heating capacity. This is an advantage from the point of view of extending the working range of the compressor.

With respect to the TSSC, it is concluded that with the variation of the swept volume of the second stage of the TSSC compressor, it is possible to improve the heating capacity compared with that the SCVI, with a minimum effect on the COP and on the discharge temperature. In practice, this can be achieved with the use of a variable speed compressor in the second stage, which allows obtaining different capacities of the compressor. This is favorable when the operating conditions change with respect to the nominal point. Hence, the compressor could work with different intermediate pressures, which implies a change in the injection ratio and the economizer capacity, and consequently allows adjusting the heating capacity to maximize the COP.

\section{Conclusions}

A comparative analysis of the compressor performance of a vapor-injection scroll compressor (SCVI) and a two-stage scroll compressor with vapor-injection (TSSC) working with high-pressure ratios is presented. The analysis was performed in terms of compressor efficiencies, heating capacity, COP, and discharge temperature. In addition, a two-stage reciprocating compressor (TSRC) was included in the study, as an alternative compressor technology available in the market for heat pump applications. Semi-empirical models of the three compressors are used in the study. The models were adjusted with experimental data obtained in a calorimetric test bench. The compressors were tested in a wide range of operating conditions using R-290 as a refrigerant. The following conclusions can be drawn from the study:

- The SCVI advantage is the easy implementation of vapor-injection from the machining point of view. Instead, the disadvantage of the SCVI is that over- and under-compression easily occurs when the operating conditions deviate from the specified designed condition due to the fixed built-in volume ratio determined by the scroll geometry. Hence, SCVI could not achieve the optimum when the operation conditions differ from the design compression ratio.

- The optimum $\mathrm{D}_{\mathrm{R}}$ of the two-stage compressors (TSSC, TSRC) taking into account the COP maximization criterion and the discharge temperature minimization criterion are very close. The COP difference is lower than $1 \%$ between the two criteria optimization and the difference in the discharge temperature is below $1 \mathrm{~K}$.

- The implementation of a finite heat transfer area in the injection mechanism (fixed size of economizer), has a negative effect on the cycle COP. That is less $2 \%$ from the COP of the ideal cycle.

- In the nominal operating conditions $\left(\mathrm{T}_{\mathrm{e}}=-15^{\circ} \mathrm{C}, \mathrm{T}_{\mathrm{c}}=50^{\circ} \mathrm{C}\right)$, the optimum $\mathrm{D}_{\mathrm{R}}$ is 0.57 for TSRC and 0.58 for TSSC. The TSSC achieves the highest COP (3.15) followed by the SCVI (2.97) and finally the TSRC (2.82). The TSSC achieves the lowest discharge temperature $\left(81.6^{\circ} \mathrm{C}\right)$ followed by the SCVI $\left(88.3^{\circ} \mathrm{C}\right)$ and finally the TSRC $\left(89.7^{\circ} \mathrm{C}\right)$.

- In the nominal operating condition, the SCVI works with lower intermediate pressure, however, its injection ratio is the highest of the three compressor technologies. The 
intermediate pressure of the two-stage compressors gets closer to the geometric mean of pressures.

- The SCVI presents better compressor efficiency for pressure ratios up to 4.5. For higherpressure ratios, the TSSC presents better compressor efficiency than SCVI and TSRC.

- Across the working range, the SCVI and TSSC present better volumetric efficiency than the TSRC, and the relative difference increases as pressure ratio increases.

- The system with SCVI presents better COP for pressure ratios below 5 due to the higher compressor efficiency in such conditions. For higher pressure ratios, the TSSC presents a better COP than the other two compressors. Nevertheless, the TSRC presents better COP than SCVI for pressure ratios higher than 7.5.

- Regarding the two-stage compressors, the TSSC achieves a lower discharge temperature than the TSRC for all the working conditions considered in the study. The SCVI achieves a lower discharge temperature than the TSSC for low compression ratios (lower than 4.8), and a lower discharge temperature than the TSRC for compression ratios below 7 .

- The subcooling is an important parameter to find the optimum intermediate pressure for heat pump applications with large temperature lift of the secondary fluid. For the studied application $\left(\mathrm{T}_{\mathrm{w}, \mathrm{n}}=45^{\circ} \mathrm{C}, \Delta \mathrm{T}_{\mathrm{w}}=20 \mathrm{~K}\right)$, the optimum intermediate pressure is achieved when the system works with subcooling around $15 \mathrm{~K}$, independently of the compressor technology. The TSSC presents higher COP in the optimum conditions and is more effective for reducing the discharge temperature. The optimum intermediate pressure is lower than the geometric mean of pressures.

- The variation of the swept volume of the high-stage compressor in a TSSC can improve the heating capacity with respect to the SCVI, with a minimum effect on the COP and on the discharge temperature compared with the optimum conditions.

The SCVI is a solution easy to implement from the industrial point of view, which allows extending the operation of single stage compressors. However, based on the results obtained in the present study, it is still far from the advantages of working with two-stage compressors in terms of efficiencies, COP, and reduction of the discharge temperature, working under extreme operating conditions.

\section{Acknowledgments}

Fernando M. Tello-Oquendo acknowledges the financial support provided by the CONVOCATORIA ABIERTA 2013-SEGUNDA FASE program, which was funded by the SENESCYT (Secretaría de Educación Superior, Ciencia, Tecnología e Innovación) (Grant No 2015-AR37665) of Ecuador. The authors would like to acknowledge Emerson Commercial and Residential Solutions for the given support to obtain the experimental data of scroll compressors and testing. In addition, the authors acknowledge the Spanish "MINISTERIO DE ECONOMIA Y COMPETITIVIDAD", through the project ref-ENE2017-83665-C2-1-P "Maximización de la eficiencia y minimización del impacto ambiental de bombas de calor para la descarbonización de la calefacción/ACS en los edificios de consumo casi nulo" for the given support.

\section{References}

[1] X. Xu, Y. Hwang, R. Radermacher, Refrigerant injection for heat pumping/airconditioning systems: literature review and challenges discussions, Int. J. Refrig. 34(2011) 402-415. 
[2] G. Ma, Q. Chai, Y. Jiang, Experimental investigation of air-source heat pump forcold regions, Int. J. Refrig. 26 (2003) 12-18.

[3] G. Ma, Q. Chai, Characteristics of an improved heat-pump cycle for cold regions, Appl. Energy 77 (2004) 235-247.

[4] G. Ma, H. Zhao, Experimental study of a heat pump system with flash-tank coupledwith scroll compressor, Energ. Build. 40 (2008) 697-701.

[5] X. Wang, Y. Hwang, R. Radermacher, Two-stage heat pump system with vaporinjectedscroll compressor using R410A as a refrigerant, Int. J. Refrig. 32 (2009)1442-1451.

[6] E. Navarro, A. Redón, J. Gonzálvez, I. Martinez, Characterization of a vapor injectionscroll compressor as a function of low, intermediate and high pressures andtemperature conditions, Int. J. Refrig. 36 (2013) 1821-1829.

[7] B. Wang, W. Shi, L. Han, X. Li, Optimization of refrigeration system with gasinjectedscroll compressor, Int. J. Refrig. 32 (2009) 1544-1554.

[8] B. Wang, W. Shi, X. Li, Numerical analysis on the effects of refrigerant injection onthe scroll compressor, Appl. Therm. Eng. 29 (2009) 37-46.

[9] X. Xu, Y. Hwang, R. Radermacher, Transient and steady-state experimental investigationof flash tank vapor injection heat pump cycle control strategy, Int. J.Refrig. 34 (2011) 1922-1933.

[10] I. Cho, S. Ko, Y. Kim, Optimization of injection holes in symmetric and asymmetricscroll compressors with vapor injection, Int. J. Refrig. 35 (2012) 850-860.

[11] C.W. Roh, M. Kim, Effects of intermediate pressure on the heating performance of aheat pump system using R410A vapor-injection technique, Int. J. Refrig. 34 (2011)1911-1921.

[12] C. Feng, W. Kai, W. Shouguo, X. Ziwen, S. Pengcheng, Investigation of the heatpump water heater using economizer vapor injection system and mixture of R22/R600a, Int. J. Refrig. 32 (2009) 509-514.

[13] S. Xu, G. Ma, Q. Liu, Z. Liu, Experiment study of an enhanced vapor injection refrigeration/heat pump system using R32, Int. J. Therm. Sci. 68 (2013) 103-109.

[14] X. Xu, Y. Hwang, R. Radermacher, Performance comparison of R410A and R32 in vapor injection cycles, Int. J. Refrig. 36 (2013) 892-903.

[15] S. Xu, X. Fan, G. Ma, Experimental investigation on heating performance of gasinjectedscroll compressor using R32, R1234yf and their 20wt\%/80wt\% mixtureunder low ambient temperature, Int. J. Refrig. 75 (2017) 286-292.

[16] F.M. Tello-Oquendo, E. Navarro-Peris, J. Gonzálvez-Maciá, New characterizationmethodology for vapor-injection scroll compressors, Int. J. Refrig. 74 (2017)526537.

[17] E.L. Winandy, J. Lebrun, Scroll compressors using gas and liquid injection: experimentalanalysis and modelling, Int. J. Refrig. 25 (2002) 1143-1156.

[18] A.K. Dutta, T. Yanagisawa, M. Fukuta, An investigation of the performance of ascroll compressor under liquid refrigerant injection, Int. J. Refrig. 24 (2001)577-587. 
[19] B. Wang, W. Shi, X. Li, Q. Yan, Numerical research on the scroll compressor withrefrigeration injection, Appl. Therm. Eng. 28 (2008) 440-449.

[20] H. Qiao, V. Aute, R. Radermacher, Transient modeling of a flash tank vapor injectionheat pump system - Part I: Model development, Int. J. Refrig. 49 (2015)169-182.

[21] N.A. James, J.E. Braun, E.A. Groll, W.T. Horton, Semi-empirical modeling andanalysis of oil flooded R410A scroll compressors with liquid injection for use invapor compression systems, Int. J. Refrig. 66 (2016) 50-63.

[22] L. Dardenne, E. Fraccari, A. Maggioni, L. Molinaroli, L. Proserpio, E. Winandy,Semiempirical modelling of a variable speed scroll compressor with vapour injection,Int. J. Refrig. 54 (2015) 76-87.

[23] M. Mathison, J. Braun, E. Groll, Performance limit for economized cycles withcontinuous refrigerant injection, Int. J. Refrig. 34 (2011) 234-242.

[24] C. Bach, E. Groll, J. Braun, W. Horton, Dual port vapor injected compression: Insystemtesting versus test stand testing, and mapping of results, Renew. Energ. 87(2016) 819833.

[25] D. Kang, J. Jeong, B. Ryu, Heating performance of a VRF heat pump system incorporatingdouble vapor injection in scroll compressor, Int. J. Refrig. 96 (2018)50-62.

[26] C. Park, H. Kang, Y. Kim, Y. Lee, Performance evaluation of a two-stage compressionheat pump system with refrigerant charge and EEV opening, Proceedings ofInternational Refrigeration and Air Conditioning Conference at Purdue, WestLafayette, IN, USA, 2006, paper 785, (2006).

[27] O. Kwon, D. Cha, C. Park, Performance evaluation of a two-stage compression heatpump system for district heating using waste energy, Energy 57 (2013) 375-381.

[28] S. Bertsch, E. Groll, Two-stage air-source heat pump for residential heating andcooling applications in northern U.S. climates, Int. J. Refrig. 31 (2008) 1282-1292.

[29] F.M. Tello Oquendo, E. Navarro Peris, J. Gonzálvez Maciá, J.M. Corberán,Performance of a scroll compressor with vapor-injection and two-stage reciprocatingcompressor operating under extreme conditions, Int. J. Refrig. 63(2016) 144-156.

[30] EN 13771-1, Compressors and condensing units for refrigeration - Performancetesting and test methods - Part 1: Refrigerant compressors, European Committee forStandardization, Brussels, Belgium: EN Standard, 2016.

[31] EN 378, Refrigerating systems and heat pumps - Safety and environmental requirements, European Committee for Standardization, Brussels, Belgium: EN Standard, 2016.

[32] EN 60079-14, Explosive atmospheres - Part 14: Electrical installations design, selectionand erection, European Committee for Standardization, Brussels, Belgium: EN Standard, 2014.

[33] EN 60079-15, Explosive atmospheres - Part 15: Equipment protection by type ofprotection " $\mathrm{n}$ ”, European Committee for Standardization, Brussels, Belgium: EN Standard, 2010. 
[34] EN 60335-2-34, Household and similar electrical appliances - Safety - Part 2-34: Particular requirements for motor-compressors, European Committee for Standardization, Brussels, Belgium: EN Standard, 2013.

[35] EN 60335-2-40:2003/A13:2012/AC:2013, Household and similar electrical appliances- Safety - Part 2-40: Particular requirements for electrical heat pumps, airconditionersand dehumidifiers, European Committee for Standardization, Brussels,Belgium: EN Standard, 2003.

[36] EN 12900, Refrigerant compressors-rating conditions, tolerances and presentationof manufacturer's performance data, European Committee for Standardization, Brussels, Belgium: EN Standard, 2013.

[37] F.M. Tello-Oquendo, E. Navarro-Peris, J. Gonzálvez-Maciá, Comparison of thecompressor losses of a scroll and a reciprocating compressor working with propane,Proceedings of the 13th IIR Gustav Lorentzen Conference, Valencia-Spain, 2018,paper 1269, (2018).

[38] F.M. Tello-Oquendo, E. Navarro-Peris, F. Barceló-Ruescas, J. GonzálvezMaciá,Semi-empirical model of scroll compressor and its extension to describe vaporinjectioncompressors. Model description and experimental validation, Int. J. Refrig.(2019), https://doi.org/10.1016/j.ijrefrig.2019.06.031 (in press).

[39] E. Navarro, E. Granryd, J.F. Urchueguía, J.M. Corberán, A phenomenological modelfor analyzing reciprocating compressors, Int. J. Refrig. 30 (2007) 1254-1265.

[40] E. Navarro, J.F. Urchueguía, J.M. Corberán, E. Granryd, Performance analysis of aseries of hermetic reciprocating compressors working with R290 (propane) and R407C, Int. J. Refrig. 30 (2007) 1244-1253.

[41] E. Lemmon, M. Huber, M. Mc Linden, NIST Standard Reference Database 23: Reference Fluid Thermodynamic and Transport Properties-refprop. NationalInstitute of Standards and Technology, Standard Reference Data Program,Gaithersburg, Version 9.0, 2010.

[42] S.A. Klein, F.L. Alvarado, EES-Engineering Equation Solver. Academic Professional Version 10.091. F-Chart Software, Madison, WI, 2017.

[43] A. Redón, E. Navarro-Peris, M. Pitarch, J. Gonzálvez-Maciá, J. Corberán, Analysisand optimization of subcritical two-stage vapor injection heat pump systems, Appl.Energy 124 (2014) 231-240.

[44] F.M. Tello-Oquendo, E. Navarro-Peris, J. Gonzálvez-Maciá, A comprehensive studyof two-stage vapor compression cycles with vapor-injection for heating applications, taking into account heat sink of finite capacity, Int. J. Refrig. 93 (2018)52-64.

[45] ASHRAE Handbook, HVAC Systems and Equipment, American Society of Heating, Refrigerating and Air-Conditioning Engineers, Inc., Atlanta, 2008. 